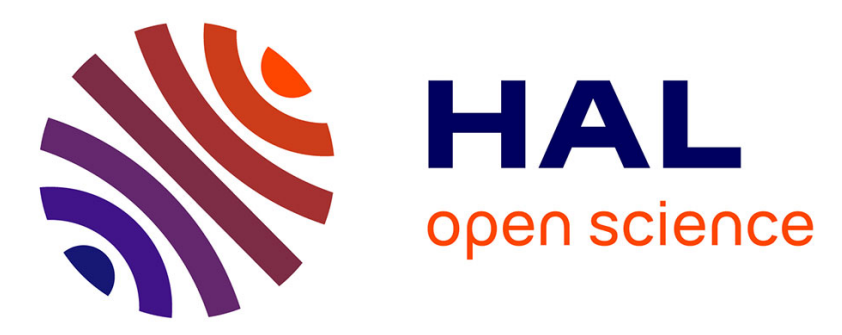

\title{
Always doing your best? Effort and performance in dynamic settings
}

Nicolas Houy, Jean-Philippe Nicolaï, Marie Claire Villeval

\section{To cite this version:}

Nicolas Houy, Jean-Philippe Nicolaï, Marie Claire Villeval. Always doing your best? Effort and performance in dynamic settings. 2017. halshs-01686501

\section{HAL Id: halshs-01686501 https://shs.hal.science/halshs-01686501}

Preprint submitted on 18 Jan 2018

HAL is a multi-disciplinary open access archive for the deposit and dissemination of scientific research documents, whether they are published or not. The documents may come from teaching and research institutions in France or abroad, or from public or private research centers.
L'archive ouverte pluridisciplinaire HAL, est destinée au dépôt et à la diffusion de documents scientifiques de niveau recherche, publiés ou non, émanant des établissements d'enseignement et de recherche français ou étrangers, des laboratoires publics ou privés. 


\title{
GATE

UMR 5824

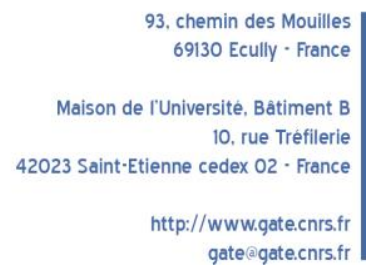

WP 1736 - December 2017

\section{Always doing your best? Effort and performance in dynamic settings}

\author{
Nicolas Houyy, Jean-Philippe Nicolaï, Marie Claire Villeval
}

\begin{abstract}
:
Achieving an ambitious goal frequently requires succeeding in a sequence of intermediate tasks, some being critical for the final outcome, and others not. However, individuals are not always able to provide a level of effort sufficient to guarantee success in all such intermediate tasks. The ability to manage effort throughout the sequence of tasks is therefore critical when resources are limited. In this paper we propose a criterion that defines the importance of a task and identifies how an individual should optimally allocate a limited stock of exhaustible efforts over tasks. We test this importance criterion in a laboratory experiment that reproduces the main features of a tennis match. We show that our importance criterion is able to predict the individuals' performance and it outperforms the Morris importance criterion that defines the importance of a point in terms of its impact on the probability of achieving the final outcome. We also find no evidence of choking under pressure and stress, as proxied by electrophysiological measures.
\end{abstract}

\section{Keywords:}

Critical ability, choking under pressure, Morris-importance, Skin Conductance Responses, experiment

JEL codes:

C72, C92, D81

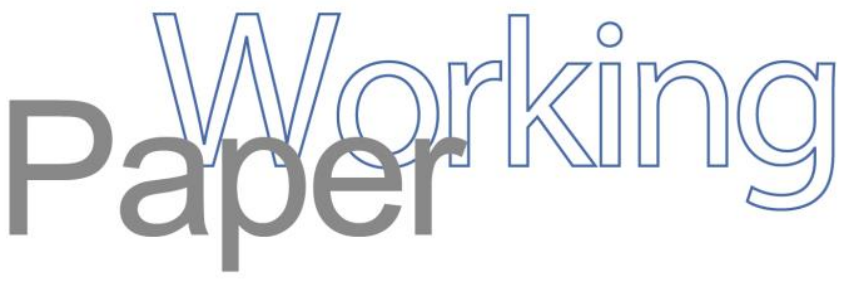




\title{
Always doing your best? \\ Effort and performance in dynamic settings *
}

\author{
Nicolas Houy ${ }^{\dagger}$ Jean-Philippe Nicolai ${ }^{\ddagger}$ Marie Claire Villeval ${ }^{\S}$
}

December 21, 2017

\begin{abstract}
Achieving an ambitious goal frequently requires succeeding in a sequence of intermediate tasks, some being critical for the final outcome, and others not. However, individuals are not always able to provide a level of effort sufficient to guarantee success in all such intermediate tasks. The ability to manage effort throughout the sequence of tasks is therefore critical when resources are limited. In this paper we propose a criterion that defines the importance of a task and identifies how an individual should optimally allocate a limited stock of exhaustible efforts over tasks. We test this importance criterion in a laboratory experiment that reproduces the main features of a tennis match. We show that our importance criterion is able to predict the individuals' performance and it outperforms the Morris importance criterion that defines the importance of a point in terms of its impact on the probability of achieving the final outcome. We also find no evidence of choking under pressure and stress, as proxied by electrophysiological measures.

JEL Classification: C72, C92, D81.

Keywords: Critical ability, choking under pressure, Morris-importance, Skin Conductance Responses, experiment
\end{abstract}

\section{Introduction}

Any professional life is composed of a myriad of trials and hardships. Each one of these sequences is a dynamic experience with various tasks to achieve, each demanding endeavours

\footnotetext{
${ }^{*}$ Acknowledgments: We are grateful to Mateus Joffily for assistance in the analysis of Skin Conductance Responses. We thank S. Chowdhury for comments on a previous version of this paper. This research has been supported by a grant of the LABEX CORTEX (ANR-11-LABX-0042) of Universite de Lyon, within the program Investissements d'Avenir (ANR-11-IDEX-007) operated by Agence Nationale de la Recherche.

${ }^{\dagger}$ Univ Lyon, CNRS, GATE Lyon St Etienne, 93 Chemin des Mouilles, F-69130, Ecully, France. houy@gate.cnrs.fr

${ }^{\ddagger}$ ETH Zürich, Chair of Integrative Risk Management and Economics, Zurichbergstrasse 18, 8032 Zürich. jnicolai@ethz.ch

${ }^{\S}$ Univ Lyon, CNRS, GATE Lyon St Etienne, 93 Chemin des Mouilles, F-69130, Ecully, France; IZA, Bonn, Germany. villeval@gate.cnrs.fr
} 
in order to meet a final, greater objective. These successive tasks do not necessarily have the same importance when it comes to achieving the final goal. Some tasks are of an irreversible nature, i.e. failing to perform them successfully will impede the achievement of the final goal (think, for example, of the completion of a $\mathrm{Ph} . \mathrm{D}$. to become an academic), while failures in other tasks (for example, being brought under pressure during a seminar presentation) can be compensated by success elsewhere (for example, making an excellent impression during the presentation of another research paper). The respective importance of these tasks will impact the behavior of agents, especially when they have to compete with others. Indeed, individuals are not always able to provide a level of effort sufficient to guarantee success in all the tasks, notably because resources are exhaustible (see for example Hancock and Desmond (2001); Hockey (2013)).

The ability to manage effort throughout the sequence of tasks is therefore critical. First, agents who are free to allocate their time and energy as they wish may be more inclined to devote more effort to more important tasks - i.e. the ones essential to achieve the final greater objective. The importance assigned to each task will certainly influence performance. Second, high stakes may generate stress that will negatively affect behavior and performance. The following question then arises: how does performance adjust to the importance of the task to be undertaken when resources are limited? One illustration outside the professional domain can be provided by a tennis match. The degree of importance attributed to each point by an individual varies according to its potential impact on the final outcome of the match. A match point is more important than the first point of the match. If an individual loses a match point, he may not be given another chance to win the match in the future. It is therefore likely that the individual will concentrate his energy on winning that point. Meanwhile, the level of stress probably increases with the importance of that point, which may affect the probability of success negatively if the individual chokes under pressure. The ability to allocate effort optimally across points (or tasks, more generally) may therefore be fundamental in winning a competition. This requires that the relationship between the importance of a task, effort and performance be identified. This is precisely the aim of this paper that considers a dynamic 
framework and a decision process that develops over time to achieve a high-stake goal.

The relationship between the importance of the task, effort allocation and performance lies at the crossroads of economics and psychology. The idea of choking under pressure was first developed to demonstrate that the importance of an issue may generate pressure that will have negative effects on performance. In particular, Baumeister (1984) and Baumeister and Showers (1986) showed that pressure increases with the existence of competition between agents (see also, e.g., Beilock and Carr (2001), DeCaro et al. (2011), Porcelli et al. (2012), Yu (2015)). Sanders and Walia (2012) insist on the fact that higher performance-contingent compensation may have a negative impact not only on performance but also on labor input if counterproductive processes decrease the marginal effectiveness of effort. Ariely et al. (2009) further showed in a series of field and lab experiments that very high monetary stakes tend to impair performance because they generate supra motivation and excess stress. Using tennis data, Cohen-Zada et al. (2017) found that males choke consistently under pressure and to a larger extent than females. ${ }^{1}$ Interestingly, recent evidence has also shown that people may choke even under the pressure of non-monetary incentives (Kali et al. (2017)).

More recently, González-Díaz et al. (2012) coined the concept of critical ability that focuses on the capacity of an agent to adapt his performance to the scale of the issue at stake. González-Díaz et al. (2012) insist in particular on individual heterogeneity in critical ability. Three interpretations of the concept are proposed by the authors. The critical ability may first be interpreted as the ability to deal with psychological pressure. Such interpretation appears close to the choking under pressure theory except that instead of being inefficient due to the pressure, the agent who possesses such a critical ability is not reactive to a stressful environment. A second interpretation considers critical ability as a special skill in allocating limited resources optimally across a set of actions. A third interpretation is the ability of an individual to understand when some situations are more crucial than others. GonzálezDíaz et al. (2012) apply this concept to tennis players. The importance of each point in a

\footnotetext{
${ }^{1}$ Using soccer penalty shootouts, Apesteguia and Palacios-Huerta (2010) found that in sequential tournaments the first kicking teams won more frequently, and suggest that psychological pressure distinct from high stakes has a detrimental effect on performance; this first-mover advantage has been challenged, however, by Kocher et al. (2012) by using a larger sample set (see also Dohmen (2008) about football competitions).
} 
match is defined in terms of the Morris-importance criterion (Morris (1977)), which is the impact of winning that precise point on the probability of winning the match. Using the Association of Tennis Professionals (ATP) Ranking as a proxy for performance, the authors analyze the relation between Morris-importance and the ATP ranking. They show that a player's higher critical ability helps predict his overall career success and conclude that success depends on the ability to respond to pressure appropriately. However, they do not formally define critical ability, their paper assuming that critical ability means performing well when Morris-importance is high.

In contrast, the present paper introduces a decision theory model in which we study critical ability and assess how performance during successive tasks is affected by the issues at stake when resources are limited. More precisely, we retain the notion of critical ability as the player's ability to focus his efforts on the most important tasks, but we differ from González-Díaz et al. (2012) in that we develop a different notion of importance. We consider a situation in which individuals have a stock of exhaustible efforts that they can deploy to increase performance only for one state each, and they have to decide how to allocate them throughout the successive states. While choosing the ideal moment to make an effort, the agent faces a trade-off between the immediate gain of being successful at a given state and the option value related to the possibility of using that effort later. This trade-off depends obviously on the state but also on the number of efforts left. The present paper then proposes a criterion - the $\mathrm{HNV}(k)$ importance $\_2$ which determines whether it is worthwhile making an effort at a given state when $k$ exhaustible efforts are left. We also compare our model with a different case whereby an agent allocates an effort to a task if the Morris-importance is higher than a given threshold. Such a situation allows us to consider at the same time the allocation of efforts and the Morrisimportance. We show that the two measures (Morris-importance and $\mathrm{HNV}(k)$-importance) are significantly different as well as the allocation variables derived from the two previous models in the seminal framework of a simplified tennis match. Although we use a tennis setting to test our model, this model aims at characterizing more generally situations involving a challenging task and the assignment of limited resources over time to reach a target, like winning in a

\footnotetext{
${ }^{2}$ HNV for Houy-Nicolai-Villeval.
} 
sport performance or succeeding at work.

In a game framework, our model would be close to a Colonel Blotto Game as introduced in Borel (1921) and recently solved by Ahmadinejad et al. (2016). ${ }^{3}$ In this family of games, players must divide their troops across different battlefields; on each battlefield, the player with the greatest number of troops wins and the winner of the game is the player who wins the highest number of battlefields. One difference with our setting is that Colonel Blotto Games are generally simultaneous games. On the contrary, we consider that the setting evolves as some tasks are performed. In this respect, the closest games to our setting are the sequential versions of Colonnel Blotto that have also been theoretically performed in Klumpp and Polborn (2006) and Konrad and Kovenock (2009). ${ }^{4}$ Indeed, they study a situation in which players compete in a sequence of simultaneous contests. Our model is also close to the contest theory developed by Tullock (1986) and Rosen (1986), which posits that effort and ability determine the probability of winning (for surveys on contest theory, see e.g. Konrad (2009), Van Long (2013), Dechenaux et al. (2015); for tests of a specific version with a tennis contest with field data, see e.g. Malueg and Yates (2010) and Ely et al. (2017) ${ }^{5}$, and in the lab, see e.g. Mago et al. (2013)). Moreover, Kovenock et al. (2015) analyzed a multi-battle contest with value complementarities among the battles. The winner of each battle is determined by a Tullock contest while the global winner is the first player who establishes a combination in the game. They demonstrate that subjects fight harder for regions that are more important for winning. In a laboratory experiment, Deck et al. (2017) confirm this prediction. However, they also show that subjects almost entirely ignore less important regions.

To test which criterion of importance better predicts behavior, we designed a laboratory experiment that reproduces the same rules of point assignment as a tennis match. We use a novel real effort task that involves using the mouse pointer to reach the center of a target appearing on the computer screen. Participants have to shoot as accurately as possible in

\footnotetext{
${ }^{3}$ Colonel Blotto Game has been experimentally analyzed by Chowdhury et al. (2013).

${ }^{4}$ Note that a dynamic sequential version of Colonnel Blotto, called Colonel Blotto Gladiator Game (Kaminsky et al. (1984), Rinott et al. (2012)), is also different since the players decide the order of the gladiators and if one gladiator wins, he stays on the battlefield.

${ }^{5}$ Using a natural experiment, they investigate whether professional tennis players are able to optimally allocate their level of risk across first and second serve. They show that professional players are very good at allocating their risk taking across different serves.
} 
the center of the target. However, the difficulty lies in the fact that a random perturbation is dynamically applied to the mouse position. The difficulty is the same for each participant. The point is won by the participant in the pair whose shot is closest to the target. The payoffs in the game depend on the final outcome of the competition. As with a tennis match, the first participant in the pair who wins at least four points with at least two points ahead of his opponent wins a round. The first participant who wins at least six rounds wins a set, and the first one who wins two sets wins the match.

The experiment consists of two treatments, the Human treatment and the Robot treatment. While in the Human treatment participants in the same session are paired together, in the Robot treatment each participant is paired with a robot. On each point the robot is randomly assigned the performance of previous participants at any moment of the match. The comparison of the two treatments indicates how strategic considerations about the opponent's play can affect how importance influences the assignment of efforts. In each treatment and for each participant, we calculate for each score the Morris-importance and the HNV $(k)$ importance. Of course, we ignore the stock of efforts available for each participant. Thus, we consider various situations in which the stock of efforts is arbitrarily set at 10, 20, 30, 40 and 50 at the start of the session. Moreover, to characterize the degree of stress experienced by the participants during a match, we use electrophysiological measures. Specifically, we continuously record the subjects' Skin Conductance Responses (SCR) that are considered as a measure of emotional arousal.

Our main findings show that the Morris-importance criterion fails to predict participants' performances while the HNV-importance criterion does predict it. This finding holds both when assuming that all participants are endowed with the same initial stock of efforts (of various sizes) in the Human treatment and when allowing each participant to differ in his stock of efforts in both treatments. Also, we do not find evidence of choking under pressure: stress, as measured by the Skin Conductance Responses, does not affect performance in the Human treatment. Furthermore, we show that subjects perform worse against humans (compared to robots). This is in contrast with notably Sheremeta (2010) who illustrates a "joy of winning" 
in contests (see also, e.g., Herbst (2016)). However, Cox (2017) focuses on over-bidding in rent-seeking contests and compares behavior in contests against other players and in ones against a robot (computer). No difference in bids between treatments at the aggregate level is observed and overbidding does not appear to be primarily driven by competitive social preferences, but rather by cognitive factors. Such results have significant implications. In particular, the design of the rewards for intermediate tasks should take into account their potential impact not only on those specific tasks but also on the dynamic allocation of effort over time. Increasing rewards for performance at a specific intermediate task may not help the performance of an agent on later, more ambitious tasks because performance on a given task depends on the rewards for that task but also on a more global perspective. Implementing different stages that the agent should reach in order to achieve a final outcome modifies the trade-off between using resources on a given task and saving them for use later.

The remainder of this paper is structured as follows. Section 2 presents the modeling assumptions and the theoretical results. Section 3 details the experimental design and procedures. Section 4 presents the experimental results. Section 5 concludes.

\section{Model}

\subsection{Set-up}

This paper considers various states and focuses on both the relationship between importance and states, and the relationship between importance and performance.

\subsubsection{States}

Let $S$ be a set of states. We add two absorbing states: $\{W\}$ where the individual wins (or where the individual has definitely reached his goal) and $\{L\}$ where he loses (or where the individual has definitely failed at reaching his goal). Let $S^{*}=S \cup\{W\} \cup\{L\}$. We denote by $\Pi\left(S^{*}\right)$ the set of probability distributions over $S^{*}$. We define a transition probability between states $p: S^{*} \times S^{*} \rightarrow[0 ; 1]$ such that $\forall s \in S^{*}, p(s,.) \in \Pi\left(S^{*}\right)$, and $p(\{W\},\{W\})=1$ and $p(\{L\},\{L\})=1$. 
First, we define the probability that, starting from a given state, the individual reaches his final goal - state $\{W\}$ - at some time.

Definition 1. (Probability of reaching the final goal) We call $P: S^{*} \rightarrow[0,1]$ the probability of reaching the final goal. This is usually referred to as the probability to hit state $\{W\}$ and is the minimal ${ }^{6}$ non-negative solution to the following system:

$$
\left\{\begin{array}{l}
P(\{W\})=1 \\
\forall s \in S \cup\{L\}, P(s)=\sum_{s^{\prime} \in S^{*}} p\left(s, s^{\prime}\right) P\left(s^{\prime}\right)
\end{array}\right.
$$

Let us provide an intuition for the linear system given in Definition 1. Let us assume an individual in state $s \in S$. He can reach states $s_{1}, s_{2}, \ldots$ with probabilities $p_{1}=p\left(s, s_{1}\right)$, $p_{2}=p\left(s, s_{2}\right), \ldots$ respectively. Conditionally on being in $s_{1}$ (resp. $\left.s_{2}, \ldots\right)$, his probability of reaching the final goal is $P\left(s_{1}\right)$ (resp. $\left.P\left(s_{2}\right), \ldots\right)$. Then, $P(s)$ is the sum of the conditional probabilities of reaching the final goal in latter states, weighted by the transition probability of reaching those states as next step.

Let us define function $s^{+}: S \rightarrow S^{*}$ as the transition function when the individual is successful at a given state. We say that an individual is successful in state $s \in S$ when he moves towards the next attainable state with the highest $P$ value. Formally, ${ }^{7}$

$$
\forall s \in S, s^{+}(s)=\arg \max _{s^{\prime} \in S^{*}, p\left(s, s^{\prime}\right)>0} P\left(s^{\prime}\right)
$$

Similarly, we consider the function $s^{-}: S \rightarrow S^{*}$ as the transition function when the individual is not successful at a given state.

$$
\forall s \in S, s^{-}(s)=\arg \min _{s^{\prime} \in S^{*}, p\left(s, s^{\prime}\right)>0} P\left(s^{\prime}\right)
$$

In order to define the importance of a given state, we use the probability function $P$ and

\footnotetext{
${ }^{6}$ If $P$ is a minimal solution and $P^{\prime}$ is any solution, then $\forall s \in S^{*}, P(s) \leq P^{\prime}(s)$. For more details, see Norris (1998). Notice that since $P$ is the minimal non negative solution, $P(\{L\})=0$.

${ }^{7}$ For the sake of simplicity, we consider the function $s^{+}$defined onto $S^{*}$ whereas it should more rigorously be set-valued.
} 
adapt the measure proposed by Morris (1977) for the tennis points case to our decision theory setting. ${ }^{8}$

Definition 2. (Morris-importance) The measure of importance of a state $s$ is given by the function $I: S \rightarrow \mathbb{R}$, defined as: $\forall s \in \mathcal{S}$,

$$
I(s)=P\left(s^{+}(s)\right)-P\left(s^{-}(s)\right) .
$$

The function $I$ corresponds to the absolute difference in the probability of reaching the final goal for a given state, according to whether the individual is successful or not at this specific state. In other words, the Morris-importance is given by the impact of being successful or not on the probability of reaching the final goal.

\subsection{Stock and allocation of efforts}

Now let us assume that the individual has some available stock of efforts. If an effort is exerted, the probability of being successful at this state is equal to one. This stock of efforts is independent of the transition probability of an individual. We assume that individuals are able to recognize the importance of a state. Efforts are exhaustible (an effort can be used only once) and limited. Note that individuals have the possibility of choosing whether to use the effort or not and they have no obligation to exhaust their stock of efforts. ${ }^{9}$ For instance, if at some state $s \in \mathcal{S}$, there exists $s^{\prime} \in \mathcal{S}$ such that $p\left(s, s^{\prime}\right)=1$, then the individual does not have any strict incentive to make an effort. We define function $V$ as the probability for an individual reaching his final goal with a given stock of efforts to be used optimally.

Definition 3. (Probability of reaching the final goal with a stock of efforts.) Consider $V: \mathbb{N} \times S^{*} \rightarrow \mathbb{R}$ the probability of reaching the final goal depending on the number of efforts left to make and at a given state. $V$ is the minimal non-negative solution to the following

\footnotetext{
${ }^{8}$ This concept is also used in Magnus and Klaassen (1998), Paserman (2007) and González-Díaz et al. (2012). However, González-Díaz et al. (2012) further use conditional probabilities, which allows them to break down the Morris-importance into the constituent probabilities of winning at the various hierarchical levels of the match.

${ }^{9}$ Of course, this is a simplification, as in reality individuals may choose finer levels of effort.
} 
system: ${ }^{10} \forall s \in S, V(0, s)=P(s)$ and $\forall k \in \mathbb{N}$ with $k>0$,

$$
\left\{\begin{array}{l}
V(k,\{W\})=1 \\
\forall s \in S \cup\{L\}, V(s)=\max \left\{V\left(k-1, s^{+}(s)\right), \sum_{s^{\prime} \in S^{*}} p\left(s, s^{\prime}\right) V\left(k, s^{\prime}\right)\right\}
\end{array}\right.
$$

In order to understand the function displayed in Definition 3, two cases should be considered. First, let us consider that one effort is used in the current state. In this case the individual is successful and the probability of reaching the final goal is equal to the probability of reaching it from the state that the individual reaches after being successful, only with one effort less. Second, if the individual does not use an effort, the probability of reaching the final goal is equal to the expected probability to reach the final goal over the next steps but with no change to his stock of efforts. The individual maximizes over the two cases, as we make the assumption that individuals are infinitely far-sighted optimizers.

We propose in this paper an importance criterion that will depend on how worthy it is to use an effort in a specific state, taking into account the number of efforts left.

Definition 4. $(\boldsymbol{H N} \boldsymbol{V}(k)$-importance) The $H N V(k)$-importance when $k>0$ efforts are left and at state $s \in \mathcal{S}$ is given by:

$$
H N V(k)=V\left(k-1, s^{+}(s)\right)-\sum_{s^{\prime} \in S^{*}} p\left(s, s^{\prime}\right) V\left(k, s^{\prime}\right)
$$

This measure is the difference between the probabilities corresponding to the two cases we described previously: either one effort is used or it is kept to be used later. In other words, this measure determines the incentive to make an effort. When it is positive, it means that it is worth using an effort. When the measure is high, it means that the incentive to use an effort is high.

\footnotetext{
${ }^{10}$ Proof of existence and uniqueness is similar to the one for function $P$ and is therefore omitted.
} 


\subsection{Differences between Morris-importance and HNV-importance}

To sum up, Morris-importance defines the concept of importance as a measure of how closer to the final goal an individual gets when being successful at an intermediate task compared to being unsuccessful. Meanwhile, HNV-importance defines the concept of importance as the incentive to make an effort when it ensures success in an intermediate task. Both definitions rely on the idea that a state should be labeled important when success at this state makes reaching the final goal more probable. Here, we propose to check for the correlations of the two definitions of importance in a simple illustration.

In order to do so, we use the seminal framework of a simplified tennis match as is widely used in the literature. This framework allows a large diversity of point importance - with both definitions - to be observed due to the ratchet effect of game points and set points for instance. More specifically, we consider two different levels of stages, an elementary stage and a crucial one. To reach the elementary stage, the individual should be successful at a minimum of 4 acts with at least 2 acts more than the number of acts for which he is unsuccessful. To reach the crucial stage the individual should be successful at six intermediate stages. If he is unsuccessful at least at six elementary stages, he fails at a crucial stage. We assume that, to reach his goal, the individual should be successful at two crucial stages and be unsuccessful at one crucial stage maximum. We calculate the correlations between Morris-importance and $\operatorname{HNV}(k)$-importance, for $k$ equal to $1,2,3,4$ and 5 , considering various arbitrary transition probabilities: $10 \%, 20 \%, 30 \%, 40 \%, 50 \%, 60 \%, 70 \%, 80 \%$ and $90 \%$. Table 1 depicts these results.

\begin{tabular}{|l|l|l|l|l|l|l|l|l|l|}
\hline Probability $p$ & $10 \%$ & $20 \%$ & $30 \%$ & $40 \%$ & $50 \%$ & $60 \%$ & $70 \%$ & $80 \%$ & $90 \%$ \\
\hline Correlation (Morris, HNV(1)) & 0.61 & 0.43 & 0.04 & -0.12 & 0.43 & -0.12 & 0.04 & 0.43 & 0.61 \\
Correlation (Morris, HNV(2)) & 0.06 & 0.04 & -0.04 & -0.04 & 0.46 & 0.07 & 0.39 & 0.74 & 0.83 \\
Correlation (Morris, HNV(3)) & 0.01 & 0.03 & 0.06 & 0.14 & 0.48 & 0.26 & 0.62 & 0.89 & 0.98 \\
Correlation (Morris, HNV(4)) & -0.00 & 0.03 & 0.07 & 0.21 & 0.46 & 0.36 & 0.69 & 0.90 & 0.97 \\
Correlation (Morris, HNV(5)) & -0.01 & 0.02 & 0.07 & 0.24 & 0.42 & 0.40 & 0.71 & 0.89 & 0.97 \\
\hline
\end{tabular}

Table 1: Correlations between Morris-importance and $\operatorname{HNV}(k)$-importance, for $k$ equal to 1 , 2, 3, 4 and 5, depending on the transition probability $p$.

The correlation between Morris-importance and HNV(1)-importance varies from 0.61 to 
-0.12. More specifically, the correlation is very low for the transition probabilities $p=30 \%$, $40 \%, 60 \%$ and $70 \%$. When $k>1$, the two measures are correlated only when the transition probability is very high. For low transition probabilities, correlations are close to zero.

We conclude that the two measures are significantly different and that this difference justifies further investigation as to the validity of the link between importance and performance. However, first, let us build the allocation variables corresponding to each measure of importance.

\subsection{Allocation variables}

Let us first focus on the "HNV(k) 01" allocation variable. We construct the $\operatorname{HNV}(k) 01$ allocation variable as follows: we consider that the match starts with players having an initial stock of efforts, $k$. Then, at the starting point, we compute whether a player has a positive incentive to use an effort using Definition 4. If that is not the case, the HNV allocation variable is 0 for that point and we proceed to the next point considering that this player keeps the same stock of efforts. If that is the case, then, the HNV allocation variable is 1 and we proceed to the next points of the actual game, only considering that, now, the player has only $k-1$ efforts left.

We also consider the case whereby an agent uses Morris-importance to allocate efforts. We construct then an equivalent "Morris $(\lambda) 01$ " allocation variable, where $\lambda$ is a threshold. If the Morris-importance is above this threshold, the Morris 01 allocation variable is equal to 1 for that point. Otherwise, the allocation variable is equal to 0 . In other words, if the Morris-importance is higher than the threshold, the agent makes an effort. Such a behavior corresponds to a naive allocation of efforts.

As previously, we calculate in the seminal framework of a simplified tennis match the allocation variables $\operatorname{Morris}(\lambda) 01$ and $\operatorname{HNV}(\mathrm{k}) 01$, for $p=0.5$ and for $k$ equal to $1,2,3,4$ and 5, considering various thresholds $\lambda: 0.1,0.2,0.3$ and 0.4 . We then calculate the correlations between $\operatorname{Morris}(\lambda) 01$ and $\operatorname{HNV}(\mathrm{k})$ 01. Table 2 depicts these results.

The allocation variables are significantly different. In the remainder of this article, we use 


\begin{tabular}{|c|l|l|l|l|}
\hline Morris threshold $\lambda$ & 0.1 & 0.2 & 0.3 & 0.4 \\
\hline Correlation (Morris 01, HNV(1) 01) & 0.16 & 0.30 & 0.09 & 0.16 \\
Correlation (Morris 01, HNV(2) 01) & 0.22 & 0.33 & 0.07 & 0.13 \\
Correlation (Morris 01, HNV(3) 01) & 0.26 & 0.25 & 0.05 & 0.05 \\
Correlation (Morris 01, HNV(4) 01) & 0.34 & 0.25 & 0.02 & 0.05 \\
Correlation (Morris 01, HNV(5) 01) & 0.37 & 0.20 & 0.01 & 0.04 \\
\hline
\end{tabular}

Table 2: Correlations between Morris 01 and $\operatorname{HNV}(k) 01$ for $p=0.5$.

an experiment to check which definition of importance is better at explaining performance.

\section{$3 \quad$ Experimental design and procedures}

\subsection{Experimental design}

In order to test these different approaches of importance and analyze which criterion has the highest predictive power of performance in a real effort task, we designed a laboratory experiment. The experiment consists of two treatments, the Human treatment and the Robot treatment. We used a between-subject design. The main difference between these two treatments is that when an individual faces a robot opponent in our game he does not have to form beliefs about how the other individual will use his efforts strategically. Let us describe each of these treatments successively.

The Human treatment In the Human treatment we pair participants at the beginning of the session. Each pair member has to compete to win a prize. To win the prize, the two competitors have to perform several rounds of a real-effort task. This task involves using the mouse pointer to reach the center of a target that is displayed on the computer screen (see Figure 1). Participants have to shoot as accurately as possible in the center of the target. The measure of performance is given by the Euclidean distance in pixels between the impact of the shot and the center of the target. The smaller the distance is, the better the performance. The difficulty of the task comes from a continuous perturbation of the mouse position that is random in each trial (giving the impression of a trembling hand). The perturbation is different across subjects but is drawn from the same distribution. In a trial, each participant has 8 


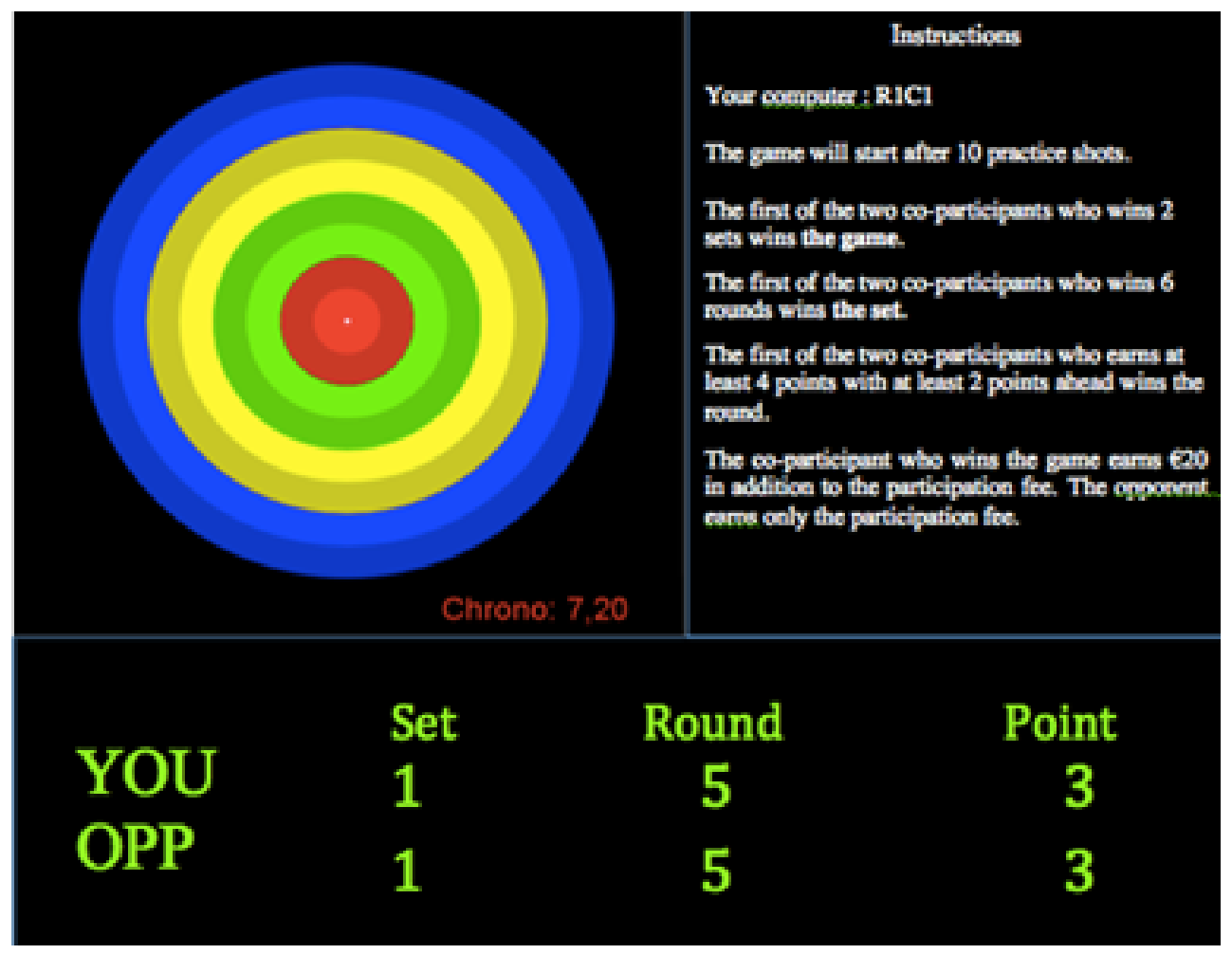

Figure 1: Screenshot of the task.

seconds maximum to shoot. If the shot has not been performed in 8 seconds, it is considered as missing in the current trial.

The payoffs in the game depend on the outcome of the competition. The winner of the game earns 20 Euros while the loser gets nothing. The game consists of several trials, rounds and sets. In a given trial, the competitor with the best performance (that is to say, the shortest distance to the center of the target) scores one point. In case of a tie between the two participants, a random draw determines which one is awarded the point. The first of the two competitors to win at least 4 points with at least 2 points ahead of the opponent wins the round. The first of the two competitors who wins 6 rounds takes the set. The first of the two competitors who wins 2 sets takes the match. There is one match in each session. As indicated in Figure 1, participants are permanently informed on the number of points, rounds and sets they and their opponent have won so far.

Before the game starts, participants can make 5 test shots and 10 practice shots and 
receive feedback on the distance to the target after each shot. The test shots are intended to familiarize them with the task. The practice shots are used to calculate each participant's ability. This captures the permanent ability of the participant, independent of his critical ability (i.e. his capacity to recognize important points and focus his efforts on these important points). The program compares the participant's performance in each of the practice shots to the performance of his opponent, taking into account all possible combinations of these shots (ignoring the shots not completed before time elapsed). At the beginning of the actual game, participants receive information about the theoretical number of chances out of 100 that they should win a point over their opponent for a given shot. ${ }^{11}$

The Robot treatment In the Robot treatment participants are informed that they are paired with a robot. It is also made common knowledge that the robot does not shoot at random: we assigned the performances of participants in previous sessions to each robot. This means that each shot is an actual shot, but played independently against the current human opponent. The robot's shot can also come from any period of the match (i.e. when the human subject plays a match point, the robot's shot is not selected among the previous match points but among all points). Here, a human participant should try to shoot as accurately as possible regardless of his beliefs about his opponent's play since this opponent cannot elaborate a strategy in response to his own play. The rules of the game are similar in this treatment to that used in the Human treatment. Like in the Human treatment, participants receive information at the beginning of the game about the theoretical number of chances out of 100 that they should win a point over their opponent. The difference is that the program compares the participant's performance in each of the practice shots to the performance in the same practice shots of different subjects in previous sessions, taking into account all possible combinations of these shots.

To study the impact of stress on performance in this game, we also measured emotional arousal continuously during the game. This gives us an index of stress. We were able to

\footnotetext{
${ }^{11}$ Indeed, in most actual sport or occupational tournaments, when they start competing, competitors are aware of their relative ability compared to that of their opponents, based on previous records of performance.
} 
record electrophysiological measures simultaneously for 12 participants per session (in total, 48 subjects were recorded in the Human treatment and 24 in the Robot treatment). Since some of the participants were not recorded, we can control for whether or not recording emotions influences performance. We take the Skin Conductance Responses (SCR) as a measure of physiological arousal associated with an emotional state. SCR were continuously recorded until the end of the session, in a noiseless environment with a stable temperature set at $21^{\circ} \mathrm{C}$. Skin conductance is analyzed in response to three events. (a) The first is during the time interval between the display of the target and the moment the shot is taken. (b) The second event of interest is the time of reception of feedback about one's own performance. (c) The third event is the time of reception of feedback on the opponent's performance (thus, on who wins the point). We imposed a minimum of 5 seconds between the second and third events when sending feedback to the subjects in order to avoid the overlapping of emotional arousals related to two different events. For the first event, SCR are analyzed within a time window with variable duration across subjects and trials since shots are self-paced (between 5 and 8 seconds). ${ }^{12}$ For the next two events, the time window is set at one to three seconds after the onset of these events to capture the onset of the response and determine whether there is a significant arousal. While emotional arousal is detected within the time window, the SCR magnitude may be given by observation after the time window. The data analysis is based on this magnitude. ${ }^{13}$

At the end of the experiment, a brief demographic questionnaire was administered, including questions on gender and age. We also asked participants if they were tennis players since familiarity with its rules may possibly help participants in our game.

\footnotetext{
${ }^{12}$ If the participant shoots in less than 5 seconds after the target appears on the screen, the window of analysis includes a minimum of five seconds. If the participant shoots between five and eight seconds, the window analysis is the time between the display of the target and the timing of the shot.

${ }^{13}$ The signal was low-pass filtered at $0.5 \mathrm{~Hz}$ offline, using a 5 th order Butterworth low-pass digital filter. The onset and peak of the SCR were detected when the first derivative of the filtered signal changed sign thanks to a routine written in Matlab (The MathWorks Inc., USA). Onsets were identified by a negative to positive zero crossing. Peaks were identified by a positive to negative zero crossing. The SCR amplitude was calculated as the difference between the signal amplitude at the peak and the onset times. It was thresholded at 0.02 $\mu \mathrm{S}$. The whole signal was visually inspected prior to further analysis and ectopic response was removed. The analysis assigns zero amplitude to the subjects without a measurable response (Dawson et al. (2007)).
} 


\begin{tabular}{crrr}
\hline & $\begin{array}{r}\text { All } \\
\text { treatments }\end{array}$ & $\begin{array}{r}\text { Human } \\
\text { treatment }\end{array}$ & $\begin{array}{r}\text { Robot } \\
\text { treatment }\end{array}$ \\
\hline Number of sessions & 6 & 4 & 2 \\
Number of participants & 103 & 70 & 33 \\
Percentage of players with SCR measured & 69.90 & 68.57 & $72.73 \mathrm{~ns} \mathrm{PT}$ \\
Percentage of males & 40.78 & 44.29 & $33.33 \mathrm{~ns} \mathrm{PT}$ \\
Mean age & $21.68(3.18)$ & $21.77(3.45)$ & $21.48(2.54) \mathrm{ns} \mathrm{MW}$ \\
Percentage with tennis experience & 28.16 & 27.14 & $30.33 \mathrm{~ns} \mathrm{PT}$ \\
Mean distance in the 10 practice shots & $7.80(0.77)$ & $7.73(0.75)$ & $7.95(0.78) \mathrm{ns}$ MW \\
\hline Notes: Standard deviations are in parentheses. ns: non significant. PT: proportion test, with one individual \\
as one independent observation. MW: Mann-Whitney tests. All tests are two-sided.
\end{tabular}

Table 3: Summary statistics on participants.

\subsection{Procedures}

The computerized experiment was conducted at GATE-LAB, Lyon, France. 103 participants were recruited from local engineering and business schools, using ORSEE (Greiner (2015)). We ran four sessions for the Human treatment and two for the Robot treatment, with respectively 70 and 33 participants. Summary statistics on participants are reported in Table 3. Based on non-parametric statistics, the composition of the two treatment samples does not differ significantly in terms of percentage of subjects with SCR measured, gender, age, practice of tennis and ability in the game. Permanent ability (distinct from critical ability) is measured as the average distance to the center of the target in the ten practice shots (excluding the shots after allowed time).

Upon arrival, participants drew a tag from a bag that determined their random assignment to a computer terminal. Next, each participant whose SCR were measured had to wash their hands with a neutral soap. Then, an experimentalist put electrodes on the non-dominant hand to be kept until the end of the session. After checking the quality of the signal recording, the set of instructions was distributed to all participants and read aloud. The participants' understanding was checked by means of a questionnaire conducted in private.

On average, a session lasted about 60 minutes, including payment. The participants were paid their earnings from the game (either 20 euros or 0 ) in addition to a 5 euros show-up fee. On average, participants earned 14.90 euros (S.D.=10.05). We paid participants individually 


\begin{tabular}{|c|c|c|c|}
\hline & $\begin{array}{c}\text { All } \\
\text { treatments }\end{array}$ & $\begin{array}{l}\text { Human } \\
\text { treatment }\end{array}$ & $\begin{array}{c}\text { Robot } \\
\text { treatment }\end{array}$ \\
\hline $\begin{array}{l}\text { Mean distance to the target } \\
\text { (in pixels) }\end{array}$ & $7.68(5.47)$ & $7.60(5.15)$ & $7.86(6.08) * * \mathrm{MW}$ \\
\hline $\begin{array}{l}\text { Mean time to shoot } \\
\text { (in milliseconds) }\end{array}$ & $3314.56(1611.42)$ & $3423.07(1687.53)$ & 3087.16 (1412.30) ns MW \\
\hline Mean number of shots & $153.54(42.95)$ & $152.94(42.79)$ & $154.82(43.92) \mathrm{ns} \mathrm{MW}$ \\
\hline $\begin{array}{l}\text { Percentage round shots } \\
\text { (i's advantage) } \\
\text { Percentage set shots }\end{array}$ & 12.68 & 12.67 & $12.70 \mathrm{~ns} \mathrm{MW}$ \\
\hline (i's advantage) & 0.94 & 0.96 & $0.88 \mathrm{~ns} \mathrm{MW}$ \\
\hline $\begin{array}{l}\text { Percentage match shots } \\
\text { (i's advantage) }\end{array}$ & 0.70 & 0.72 & $0.67 \mathrm{~ns} \mathrm{MW}$ \\
\hline Percentage of winning & 4951 & 5000 & 4848 ns binomial test \\
\hline Mean Morris & $0.05(0.06)$ & $0.05(0.06)$ & $0.05(0.06) \mathrm{ns} \mathrm{MW}$ \\
\hline Mean HNV & $0.09(0.29)$ & $0.09(0.28)$ & $0.10(0.30) \mathrm{ns} M W$ \\
\hline $\begin{array}{l}\text { Mean SCR amplitude } \\
\text { at presentation of the target } \\
\text { Mean SCR amplitude }\end{array}$ & $0.03(0.12)$ & $0.02(0.09)$ & $0.04(0.17)$ ns MW \\
\hline $\begin{array}{l}\text { at feedback on own score } \\
\text { Mean SCR amplitude }\end{array}$ & $0.122(0.178)$ & $0.113(0.164)$ & $0.145(0.208) \mathrm{ns} \mathrm{MW}$ \\
\hline at feedback on trial outcome & $0.110(0.178)$ & $0.103(0.175)$ & $0.126(0.183)$ ns MW \\
\hline
\end{tabular}

in cash and in private in a separate room immediately after the end of the session.

\section{Experimental Results}

Table 4 gives a brief overview of descriptive statistics relative to the two treatments. The last column reports non-parametric tests comparing the two treatments. In these tests, one mean value for each individual for the whole game is taken as one independent observation.

Table 4 indicates a significant difference between treatments in terms of performance (distance to the target, $\mathrm{p}=0.046$ ), but no difference regarding time to shoot, duration of the match, percentage of round/set and game shots to the advantage of the individual, and emotional arousal. We introduce our first result. 
Result 1: Approaches based either on the nature of the shot (round/set/match shots vs. regular shots) or on the Morris criterion of importance fail to predict participants' shot performance. Players do not choke under pressure.

Support to Result 1. To compare the predictive values of our different importance criteria, we use an econometric analysis in which the dependent variable is the player's performance captured by the distance of the shot from the center of the target in each trial. We estimate linear regressions ${ }^{14}$ with robust standard errors clustered at the individual level. In all the econometric models reported in the remainder of this section, the independent variables include the complexity of the current shot, the time to shoot and the shot number in the game. The "Distance practice" variable is the mean distance to the center of the target in the ten practice shots: the higher this distance is, the lower is the player's permanent ability. Complexity is measured by the sum of the net perturbations of the trajectory during 250 milliseconds before the shot. ${ }^{15}$ We control for whether the player's electrodermal responses were recorded or not and for the magnitude of the emotional arousal at the time of the shot. ${ }^{16}$ We also include controls for gender, age and practice of tennis.

First, we consider a notion of effort assignment based on the nature of the shot. Precisely, we test whether the distance to the target is affected by the fact that relative performance for that shot determines whether the player or his opponent wins either a round, a set or the match, compared to a regular shot (omitted category). The first three columns of Table 5 report these regressions for the two treatments pooled together (model (1)), the Human treatment (model (2)) and the Robot treatment (model (3)). In model (1), we include a dummy variable indicating whether the player is interacting with a human opponent or with

\footnotetext{
${ }^{14}$ We de not need to use tobit since only $0.41 \%$ of the data are censored at 0.

${ }^{15}$ Every 50ms, we draw two integer numbers, $\mathrm{lx}$ and ly in the interval $[-5 ; 5]$ with uniform probability. The player's pointer is modified by $\mathrm{lx}$ pixels on the $\mathrm{x}$-axis and ly pixels on the $\mathrm{y}$-axis. Let $L x=\left(l x_{i}\right)_{i \in[1 ; 5]}$ be the sequence of the five values of lx drawn before the player shot and $L y=\left(l y_{i}\right)_{i \in[1 ; 5]}$ be the sequence of the five values of ly drawn before the player shot. The value we report is $\left.S=\sqrt{(}\left(\sum_{i=1}^{5} l x_{i}\right)^{2}+\left(\sum_{i=1}^{5} l y_{i}\right)^{2}\right)$. Then, $\mathrm{S}$ is the distance between the positions of the pointer 0.25 seconds before the player's shot and at the time of the shot that is generated by the noise alone.

${ }^{16}$ We also tested the potential influence on the current distance of the emotional arousal experienced during the previous shot at the time of the feedback on one's score and on the trial's outcome. This requires dropping the observations relative to the first shot in the game. Since these two SCR measures were never significant, we do not include these variables in the regressions reported here and keep the data of all periods.
} 
a robot.

In Table 5, model (2) indicates that, in most cases, round, set and match shots have no specific impact on performance compared to regular shots. Exceptions in the Human treatment are that performance is significantly better when it determines whether the player will win the round or whether the opponent will win the match. In the Robot treatment, it is marginally significantly better when it decides whether the opponent will win the round. Overall, however, considering only the local stake of a shot has very limited predictive value.

Our second measure of optimal effort assignment is based on the Morris criterion. It is calculated for each shot based on the percentage of ex ante chances each competitor has of winning the game considering his relative performance in the ten practice shots. The last two columns of Table 5 report the estimates of the model in which we consider the value of the Morris-importance for each shot instead of the stake for the shot. Model (4) is for the Human treatment and model (5) for the Robot treatment. These two models show that Morrisimportance attracts the predicted negative sign but is far from reaching standard significance levels in any treatment. We then consider HNV-importance and present our second result.

Result 2: The HNV-importance for the optimal assignment of efforts predicts players' performance. This finding holds in the Human treatment when assuming that all players are endowed with the same stock of effort and in both treatments when allowing each player to differ in his stock of efforts.

Support for Result 2. In a dynamic setting, we consider that all players start the game with a stock of either 10,20,30, 40 or 50 efforts to assign during the match. The player does not take into account the other player's response to his own play. We compute dynamically along the match on which points a subject should optimally use these 10, 20, 30, 40 or 50 efforts, based on his relative ability in the ten practice shots and knowing the actual duration of the game against his actual opponent. Indeed, we assume that players are able to form an expectation about the overall duration of the match, knowing their relative ability. We consider for each trial the incentive players have to use one effort, considering the stock of efforts left. For each initial stock of efforts among 10,20,30, 40, 50 we build the HNV-importance variable that 


\begin{tabular}{|c|c|c|c|c|c|}
\hline \multirow{4}{*}{$\begin{array}{r}\text { Dep. } \\
\text { variable: } \\
\text { Distance }\end{array}$} & \multicolumn{3}{|c|}{ Nature of the shoot } & \multicolumn{2}{|c|}{ Morris criterion } \\
\hline & \multirow[t]{2}{*}{ All } & \multirow{3}{*}{$\begin{array}{r}\text { Human } \\
\text { treatment }\end{array}$} & \multirow{3}{*}{$\begin{array}{r}\text { Robot } \\
\text { treatment } \\
(3)\end{array}$} & \multirow{3}{*}{$\begin{array}{r}\text { Human } \\
\text { treatment } \\
(4)\end{array}$} & \multirow{3}{*}{$\begin{array}{r}\text { Robot } \\
\text { treatment } \\
(5)\end{array}$} \\
\hline & & & & & \\
\hline & (1) & & & & \\
\hline Human opponent & $\begin{array}{c}4.412^{* * *} \\
(1.023)\end{array}$ & - & - & - & 7 \\
\hline Complexity & $\begin{array}{c}0.634^{* * *} \\
(0.011)\end{array}$ & $\begin{array}{r}0.632^{* * *} \\
(0.015)\end{array}$ & $\begin{array}{r}0.640^{* * *} \\
(0.018)\end{array}$ & $\begin{array}{r}0.631^{* * *} \\
(0.015)\end{array}$ & $\begin{array}{r}0.640 * * * \\
(0.018)\end{array}$ \\
\hline Round shot for $\mathrm{i}$ & -0.133 & $-0.334^{* * *}$ & 0.288 & - & (7) \\
\hline & $(0.127)$ & $(0.104)$ & $(0.313)$ & & \\
\hline Set shot for i & -0.348 & -0.271 & -0.502 & - & - \\
\hline & $(0.243)$ & $(0.304)$ & $(0.404)$ & & \\
\hline Match shot for $\mathrm{i}$ & 0.065 & 0.192 & -0.143 & - & - \\
\hline & $(0.256)$ & $(0.293)$ & $(0.508)$ & & \\
\hline Round shot for $\mathrm{j}$ & -0.097 & 0.012 & $-0.309 *$ & - & - \\
\hline & $(0.080)$ & $(0.087)$ & $(0.159)$ & & \\
\hline Set shot for $\mathrm{j}$ & -0.317 & -0.391 & -0.220 & - & - \\
\hline & $(0.252)$ & $(0.322)$ & $(0.407)$ & & \\
\hline Match shot for $\mathrm{j}$ & $-0.535^{* *}$ & $-0.973^{* * *}$ & 0.380 & - & - \\
\hline & $(0.244)$ & $(0.247)$ & $(0.508)$ & & \\
\hline Morris criterion & - & - & - & -0.023 & -2.109 \\
\hline & & & & $(0.547)$ & $(2.274)$ \\
\hline Distance Practice & $0.933^{* * *}$ & $0.354^{* * *}$ & $0.980^{* * *}$ & $0.354 * * *$ & $0.943^{* * *}$ \\
\hline & $(0.076)$ & $(0.108)$ & $(0.085)$ & $(0.108)$ & $(0.063)$ \\
\hline \multirow[t]{2}{*}{ Distance Practice*Human opponent } & $-0.576^{* * *}$ & - & - & & - \\
\hline & $(0.135)$ & - & - & & \\
\hline \multirow[t]{2}{*}{ Time to shoot } & $<-0.001$ & $<-0.001$ & $<-0.001$ & $<0.001$ & $<-0.001$ \\
\hline & $(<0.001)$ & $(<0.001)$ & $(<0.001)$ & $(<0.001)$ & $(<0.001)$ \\
\hline \multirow[t]{2}{*}{ Shot number } & $<-0.001$ & -0.001 & $<0.001$ & -0.001 & 0.002 \\
\hline & $(0.001)$ & $(0.001)$ & $(0.002)$ & $(0.001)$ & $(0.003)$ \\
\hline \multirow[t]{2}{*}{ SCR measure } & -0.062 & -0.015 & -0.127 & -0.014 & -0.148 \\
\hline & $(0.063)$ & $(0.080)$ & $(0.096)$ & $(0.081)$ & $(0.098)$ \\
\hline \multirow[t]{2}{*}{ SCR magnitude } & $0.564^{*}$ & -0.050 & $0.924^{* * *}$ & -0.054 & $0.933^{* * *}$ \\
\hline & $(0.291)$ & $(0.341)$ & $(0.302)$ & $(0.340)$ & $(0.296)$ \\
\hline \multirow[t]{2}{*}{ Male } & -0.064 & -0.021 & -0.072 & -0.02 & -0.072 \\
\hline & $(0.058)$ & $(0.069)$ & $(0.133)$ & $(0.069)$ & $(0.129)$ \\
\hline \multirow[t]{2}{*}{ Age } & $0.012^{* *}$ & $0.019 * * *$ & -0.019 & $0.019 * * *$ & -0.021 \\
\hline & $(0.005)$ & $(0.007)$ & $(0.012)$ & $(0.007)$ & $(0.014)$ \\
\hline \multirow[t]{2}{*}{ Tennis } & -0.102 & -0.111 & -0.080 & -0.109 & -0.064 \\
\hline & $(0.066)$ & $(0.083)$ & $(0.093)$ & $(0.084)$ & $(0.084)$ \\
\hline \multirow[t]{2}{*}{ Constant } & $-4.631^{* * *}$ & -0.407 & $-4.129^{* * *}$ & -0.431 & -3.821 \\
\hline & $(0.548)$ & $(0.751$ & $(0.643)$ & $(0.743)$ & $(0.515)$ \\
\hline Nb observations & 15740 & 10640 & 5100 & 10640 & 5100 \\
\hline $\mathrm{Nb}$ clusters & 103 & 70 & 33 & 70 & 33 \\
\hline $\mathrm{F}$ & 416.28 & 256.39 & 412.51 & 348.18 & 410.12 \\
\hline $\mathrm{p}>\mathrm{F}$ & $<0.001$ & $<0.001$ & $<0.001$ & $<0.001$ & $<0.001$ \\
\hline $\mathrm{R} 2$ & 0.219 & 0.237 & 0.193 & 0.236 & 0.193 \\
\hline
\end{tabular}

Table 5: Determinants of performance, including the nature of the shot or Morris-importance. 
takes value 1 or 0 , depending on whether the effort for the given stock should be invested or not in the current shot, as determined by our model.

In Table 6, we estimate five models explaining the distance to the target of the current shot in the Human treatment, one for each initial stock of optimal effort assignment between 10 and 50. We add the HNV criterion to the previous independent variables (Distance practice, complexity, time to shoot, shot number, recording of SCR, magnitude of SCR, gender, age, and practice of tennis). Table A1 in Appendix displays the same models for the Robot treatment.

In all models but one (when we consider 40 optimal efforts to assign) in the Human treatment, the HNV criterion predicts the player's performance at the $5 \%$ or at the $1 \%$ significance level. In contrast, Table A1 in the Appendix shows that in the Robot treatment the HNV allocation variable does not impact performance. This surprising finding indicates that when the player should rationally use one effort from his stock according to HNV theory, this indeed improves his performance by reducing the distance to the target, but exclusively when the player interacts with a human opponent. ${ }^{17}$ This suggests that when interacting with a robot, the impossibility of predicting one's opponent effort in a specific moment of the match affects the ability of a player to assign his efforts according to the HNV-importance.

In each regression reported in Table 6, we forced each player to use the same initial stock of efforts. We now relax this constraint by allowing for individual heterogeneity in optimal effort assignment. In other words, we now consider the heterogeneity in individuals' critical ability, as shown by González-Díaz et al. (2012) concerning tennis players. To do so, we estimate for each individual which initial stock of efforts, between 10 and 50, best fits his distance to the target throughout the game, with a linear model and robust standard errors. We consider five estimations for each individual, one for each possible initial stock of efforts, and include as independent variables the HNV allocation variable for that stock, the complexity of the current shot, the time to shoot, and the shot number. We compare the five regressions for each individual and retain the model -therefore the initial stock of optimal efforts for this player- that gives the highest t-value to the HNV allocation variable. ${ }^{18}$ Next, in Table 7 we

\footnotetext{
${ }^{17}$ Note that we also tested the same model considering the assignment of more than 50 units of effort. The HNV allocation variable remains significant at the $1 \%$ level. To save space, we omit these regressions here.

${ }^{18}$ For some individuals we have to reject the five regressions and assign to the player a missing HNV allo-
} 


\begin{tabular}{rccccc}
\hline Dep. variable: Distance to center & $\begin{array}{c}10 \text { efforts } \\
(1)\end{array}$ & $\begin{array}{c}20 \text { efforts } \\
(2)\end{array}$ & $\begin{array}{c}30 \text { efforts } \\
(3)\end{array}$ & $\begin{array}{c}40 \text { efforts } \\
(4)\end{array}$ & $\begin{array}{c}50 \text { efforts } \\
(5)\end{array}$ \\
\hline Complexity & $0.631^{* * *}$ & $0.632^{* * *}$ & $0.631^{* * *}$ & $0.631^{* * *}$ & $0.632^{* * *}$ \\
& $(0.015)$ & $(0.015)$ & $(0.015)$ & $(0.015)$ & $(0.015)$ \\
HNV allocation variable & $-0.305^{* *}$ & $-0.316^{* * *}$ & $-0.342^{* * *}$ & -0.130 & $-0.930^{* * *}$ \\
& $(0.130)$ & $(0.115)$ & $(0.097)$ & $(0.097)$ & $(0.253)$ \\
Distance Practice & $0.353^{* * *}$ & $0.354^{* * *}$ & $0.354^{* * *}$ & $0.357^{* * *}$ & $0.356^{* * *}$ \\
& $(0.108)$ & $(0.108)$ & $(0.107)$ & $(0.108)$ & $(0.109)$ \\
Time to shoot & $<0.001$ & $<0.001$ & $<0.001$ & $<0.001$ & $<0.001$ \\
& $(<0.001)$ & $(<0.001)$ & $(<0.001)$ & $(<0.001)$ & $(<0.001)$ \\
Shot number & -0.001 & -0.001 & -0.001 & -0.001 & -0.001 \\
& $(0.001)$ & $(0.001)$ & $(0.001)$ & $(0.001)$ & $(0.001)$ \\
SCR measure & -0.015 & -0.016 & -0.008 & -0.013 & -0.013 \\
& $(0.079)$ & $(0.079)$ & $(0.080)$ & $(0.080)$ & $(0.080)$ \\
SCR magnitude & -0.049 & -0.046 & -0.059 & -0.043 & -0.051 \\
& $(0.340)$ & $(0.341)$ & $(0.342)$ & $(0.344)$ & $(0.343)$ \\
Male & -0.019 & -0.021 & -0.019 & -0.017 & -0.023 \\
& $(0.069)$ & $(0.069)$ & $(0.069)$ & $(0.070)$ & $(0.069)$ \\
Age & $0.019^{* * *}$ & $0.019 * * *$ & $0.019^{* * *}$ & $0.019^{* * *}$ & $0.018^{* * *}$ \\
& $(0.007)$ & $(0.007)$ & $(0.007)$ & $(0.007)$ & $(0.007)$ \\
Tennis & -0.112 & -0.110 & -0.107 & -0.108 & -0.112 \\
& $(0.083)$ & $(0.083)$ & $(0.083)$ & $(0.083)$ & $(0.083)$ \\
Constant & -0.417 & -0.399 & -0.367 & -0.446 & -0.454 \\
& $(0.750)$ & $(0.752)$ & $(0.748)$ & $(0.751)$ & $(0.757)$ \\
\hline R $>\mathrm{F} 2$ & $<0.001$ & $<0.001$ & $<0.001$ & $<0.001$ & $<0.001$ \\
$\mathrm{~F}$ & 346.16 & 344.96 & 345.41 & 350.66 & 367.30 \\
Nb clusters & 10640 & 10640 & 10640 & 10640 & 10640 \\
Nb observations & 0.236 & 0.236 & 0.237 & 0.236 & 0.236 \\
\hline
\end{tabular}

Note: All models are OLS regressions with robust standard errors (in parentheses) clustered at the individual level. ${ }^{* * *},{ }^{* *}$ and $*$ indicate significance at the $1 \%$ level, $5 \%$ level and $10 \%$ level, respectively.

Table 6: Determinants of performance in the Human treatment, based on the homogenous HNV-importance. 
report three regressions of the distance to the target, one for the treatments pooled together (1), one for the Human treatment (2) and one for the Robot treatment (3). The independent variables are the same as in Table 6, except that the HNV criterion now corresponds to different stocks of optimal effort assignment across players, as determined by the individual regressions.

Table 7 shows that if we allow for individual heterogeneity in the endowment in terms of effort stock, a shot with a higher importance according to the HNV allocation variable significantly increases the player's performance. This is observed regardless of whether the opponent is a human (model (2)) or a robot (model (3)). While the findings of Tables 6 and 7 are consistent, Table 7 contradicts those of Table A1. This suggests that players behave more heterogeneously when they are facing a robot, as a general approach of effort assignment fails to predict performance in this case.

We wish to determine whether Result 2 derives from the possibility of allocating efforts or from the fact that the agent takes into account the option-value to decide whether he makes an effort or not. The allocation variable $\operatorname{Morris}(\lambda) 01$ determined in Section 2 corresponds to a naive allocation of efforts. Therefore, we determine whether the allocation variable Morris $(\lambda)$ 01 explains performance. In Table 8, we estimate four models explaining the distance to the target of the current shot in the Human treatment and in the Robot treatment. We consider the following thresholds: $0.1,0.2,0.3$ and 0.4 . We demonstrate that $\operatorname{Morris}(\lambda) 01$ is not significant and then does not explain performance. We conclude that Result 2 does not come from the possibility of allocating efforts but from the method used to calculate how to allocate effort. We finally introduce our last result.

Result 3: Emotional arousal hinders performance only when players are facing a robot, possibly because they cannot predict their opponent's strategy.

Support for Result 3. Tables 5 to 7 show that having one's emotions recorded does not impact performance. For the average player, all else being constant, having a robot opponent

cation variable. This occurs when the HNV allocation variable receives a positive coefficient (indicating that performance decreases when the point is more important in the sense of the HNV model). This corresponds to $7.14 \%$ of the players in the Human treatment and to $9.09 \%$ of the players in the Robot treatment (the difference is not statistically significant according to a proportion test). These observations are kept in the regressions and we include a dummy variable ("Missing HNV allocation") to the other independent variables. 


\begin{tabular}{|c|c|c|c|}
\hline $\begin{array}{r}\text { Dep. variable: } \\
\text { Distance to center }\end{array}$ & $\begin{array}{l}\text { All treatments } \\
(1)\end{array}$ & $\begin{array}{c}\text { Human treatment } \\
(2)\end{array}$ & $\begin{array}{c}\text { Robot treatment } \\
\text { (3) }\end{array}$ \\
\hline Human opponent & $3.896^{* * *}(0.958)$ & - & - \\
\hline Complexity & $0.640 * * *(0.017)$ & $0.631^{* * *}(0.015)$ & $0.640 * * *(0.018)$ \\
\hline Complexity*human & $-0.010(0.023)$ & - & - \\
\hline HNV allocation variable & $-0.898 * * *(0.170)$ & $-0.897^{* * *}(0.080)$ & $-0.898^{* * *}(0.171)$ \\
\hline HNV allocation variable*human & $0.001(0.187)$ & - & - \\
\hline Missing HNV allocation variable & $-0.145(0.090)$ & $-0.171^{* * *}(0.054)$ & $-0.145(0.091)$ \\
\hline Missing*human & $-0.026(0.105)$ & - & - \\
\hline Distance Practice & $0.978 * * *(0.068)$ & $0.339 * * *(0.114)$ & $0.978 * * *(0.068)$ \\
\hline Distance Practice*human & $-0.639 * * *(0.133)$ & - & - \\
\hline Time to shoot & $<-0.001(<0.001)$ & $<0.001(<0.001)$ & $<-0.001(<0.001)$ \\
\hline Time to shoot*human & $<0.001(<0.001)$ & - & - \\
\hline Shot number & $<0.001(0.002)$ & $-0.001(0.001)$ & $<0.001(0.002)$ \\
\hline Shot number*human & $-0.002(0.002)$ & - & - \\
\hline SCR measure & $-0.093(0.098)$ & $-0.031(0.083)$ & $-0.093(0.099)$ \\
\hline SCR measure *human & $0.062(0.129)$ & - & - \\
\hline SCR magnitude & $0.880 * * *(0.280)$ & $-0.058(0.342)$ & $0.880^{* * *}(0.283)$ \\
\hline SCR magnitude ${ }^{*}$ human & $-0.938^{* *}(0.441)$ & - & - \\
\hline Male & $-0.047(0.124)$ & $-0.002(0.072)$ & $-0.047(0.125)$ \\
\hline Male*human & $0.049(0.143)$ & - & - \\
\hline Age & $-0.016(0.012)$ & $0.018^{* * *}(0.006)$ & $-0.016(0.012)$ \\
\hline Age*human & $0.034^{* *}(0.013)$ & - & - \\
\hline Tennis & $-0.068(0.095)$ & $-0.103(0.084)$ & $-0.068(0.096)$ \\
\hline Tennis*human & $-0.035(0.126)$ & - & - \\
\hline Constant & $-4.122^{* * *}(0.542)$ & $-0.226(0.791)$ & $-4.122^{* * *}(0.548)$ \\
\hline $\mathrm{Nb}$ observations & 15740 & 10640 & 5100 \\
\hline $\mathrm{Nb}$ clusters & 103 & 70 & 33 \\
\hline $\mathrm{F}$ & 441.56 & 319.72 & 492.06 \\
\hline $\mathrm{p}>\mathrm{F}$ & $<0.001$ & $<0.001$ & $<0.001$ \\
\hline $\mathrm{R} 2$ & 0.221 & 0.239 & 0.194 \\
\hline
\end{tabular}

Note: All models are OLS regressions with robust standard errors (in parentheses) clustered the individual level. ${ }^{* * *},{ }^{* *}$ and ${ }^{*}$ indicate significance at the $1 \%$ level, $5 \%$ level and $10 \%$ level, respectively.

Table 7: Determinants of performance in the Human treatment, based on the heterogeneous HNV-importance. 


\begin{tabular}{|c|c|c|c|c|c|c|c|c|}
\hline \multirow[t]{2}{*}{ Dep. variable: Distance to center } & \multicolumn{4}{|c|}{ Human treatment } & \multicolumn{4}{|c|}{ Robot treatment } \\
\hline & $\lambda=0.1$ & $\lambda=0.2$ & $\lambda=0.3$ & $\lambda=0.4$ & $\lambda=0.1$ & $\lambda=0.2$ & $\lambda=0.3$ & $\lambda=0.4$ \\
\hline \multirow[t]{2}{*}{ Complexity } & $0.640^{* * *}$ & $0.640^{* * *}$ & $0.640^{* * *}$ & $0.640^{* * *}$ & $0.631^{* * *}$ & $0.631^{* * *}$ & $0.631^{* * *}$ & $0.631^{* * *}$ \\
\hline & $(0.018)$ & $(0.018)$ & $(0.018)$ & $(0.018)$ & $(0.015)$ & $(0.015)$ & $(0.015)$ & $(0.015)$ \\
\hline \multirow[t]{2}{*}{$\operatorname{Morris}(\lambda) 01$} & -0.101 & -0.219 & -0.096 & 0.255 & -0.020 & -0.206 & -0.118 & -0.081 \\
\hline & $(0.245)$ & $(0.270)$ & $(0.491)$ & $(1.093)$ & $(0.097)$ & $(0.196)$ & $(0.161)$ & $(0.236)$ \\
\hline \multirow[t]{2}{*}{ Distance in practice } & $0.969 * * *$ & $0.971^{* * *}$ & $0.971^{* * *}$ & $0.971^{* * *}$ & $0.354^{* * *}$ & $0.354^{* * *}$ & $0.354^{* * *}$ & $0.354^{* * *}$ \\
\hline & $(0.079)$ & $(0.082)$ & $(0.082)$ & $(0.082)$ & $(0.107)$ & $(0.107)$ & $(0.107)$ & $(0.107)$ \\
\hline \multirow[t]{2}{*}{ Time to shoot } & $<-0.001$ & $<-0.001$ & $<-0.001$ & $<-0.001$ & $<0.001$ & $<0.001$ & $<0.001$ & $<0.001$ \\
\hline & $(<0.001)$ & $(<0.001)$ & $(<0.001)$ & $(<0.001)$ & $(<0.001)$ & $(<0.001)$ & $(<0.001)$ & $(<0.001)$ \\
\hline \multirow[t]{2}{*}{ Shot number } & 0.001 & 0.001 & 0.001 & 0.001 & -0.001 & -0.001 & -0.001 & -0.001 \\
\hline & $(0.002)$ & $(0.002)$ & $(0.002)$ & $(0.002)$ & $(0.001)$ & $(0.001)$ & $(0.001)$ & $(0.001)$ \\
\hline \multirow[t]{2}{*}{ SCR measure } & -0.133 & -0.132 & -0.133 & -0.131 & -0.014 & -0.014 & -0.014 & -0.014 \\
\hline & $(0.094)$ & $(0.094)$ & $(0.094)$ & $(0.094)$ & $(0.079)$ & $(0.079)$ & $(0.079)$ & $(0.079)$ \\
\hline \multirow[t]{2}{*}{ SCR amplitude } & $0.928^{* * *}$ & $0.911^{* * *}$ & $0.915^{* * *}$ & $0.919 * * *$ & -0.055 & -0.058 & -0.054 & -0.054 \\
\hline & $(0.297)$ & $(0.296)$ & $(0.298)$ & $(0.297)$ & $(0.340)$ & $(0.339)$ & $(0.340)$ & $(0.340)$ \\
\hline \multirow[t]{2}{*}{ Male } & -0.068 & -0.066 & -0.067 & -0.065 & -0.020 & -0.020 & -0.020 & -0.020 \\
\hline & $(0.131)$ & $(0.133)$ & $(0.132)$ & $(0.133)$ & $(0.069)$ & $(0.069)$ & $(0.069)$ & $(0.069)$ \\
\hline \multirow[t]{2}{*}{ Age } & -0.019 & -0.019 & -0.019 & -0.019 & $0.019^{* * *}$ & $0.019^{* * *}$ & $0.019^{* * *}$ & $0.019 * * *$ \\
\hline & $(0.012)$ & $(0.012)$ & $(0.012)$ & $(0.012)$ & $(0.007)$ & $(0.007)$ & $(0.007)$ & $(0.007)$ \\
\hline \multirow[t]{2}{*}{ Tennis } & -0.078 & -0.080 & -0.080 & -0.079 & -0.108 & -0.108 & -0.109 & -0.109 \\
\hline & $(0.089)$ & $(0.091)$ & $(0.092)$ & $(0.091)$ & $(0.083)$ & $(0.083)$ & $(0.083)$ & $(0.083)$ \\
\hline \multirow[t]{2}{*}{ Constant } & $-4.083^{* * *}$ & $-4.100 * * *$ & $-4.091^{* * *}$ & $-4.090 * * *$ & -0.437 & -0.443 & -0.434 & -0.437 \\
\hline & $(0.601)$ & $(0.616)$ & $(0.610)$ & $(0.610)$ & $(0.745)$ & $(0.741)$ & $(0.742)$ & $(0.745)$ \\
\hline Nb observations & 5100 & 5100 & 5100 & 5100 & 10640 & 10640 & 10640 & 10640 \\
\hline $\mathrm{Nb}$ clusters & 33 & 33 & 33 & 33 & 70 & 70 & 70 & 70 \\
\hline $\mathrm{F}$ & 430.96 & 412.05 & 410.39 & 420.25 & 346.80 & 347.67 & 394.63 & 371.43 \\
\hline $\mathrm{p}>\mathrm{F}$ & $<0.001$ & $<0.001$ & $<0.001$ & $<0.001$ & $<0.001$ & $<0.001$ & $<0.001$ & $<0.001$ \\
\hline $\mathrm{R} 2$ & 0.192 & 0.192 & 0.192 & 0.192 & 0.236 & 0.236 & 0.236 & 0.236 \\
\hline
\end{tabular}

Note: All models are OLS regressions with robust standard errors (in parentheses) clustered at the individual level. *** indicates significance at the $1 \%$ level.

Table 8: Determinants of performance, with $\operatorname{Morris}(\lambda) 01$ allocation variable 
has a positive impact on performance, except for those subjects who experience a greater SCR magnitude. In contrast, SCR never affects performance in the Human treatment. A possible explanation is that on average individuals feel less discouraged when losing points when they know they can ignore the strategy of the opponent since the robot is not reacting to their play. But the sub-sample of players who are more emotionally aroused when playing against a robot may see the competitive situation as more threatening than when opposed to a human, which affects their performance negatively. Blascovich et al. (2004) and Moore et al. (2012) for example found a correlation between perception of threat, physiological reaction and performance in sport competitions; Buckert et al. (2015) have shown that perceiving competition as a threat tends to decrease a player's performance in the lab. A possible interpretation is that in our game, emotionally aroused players may be those who see a competition against a robot as more threatening than a competition against a human because they cannot predict the importance of the shot for the robot opponent.

Finally, it should be noted that almost all models show that performance decreases with the level of complexity of the shot and the player's age, and improves with his permanent ability. Other controls are never significant.

\section{Conclusion}

Successive tasks often do not have the same importance when it comes to achieving a final goal. A clear illustration is given by a tennis match but other examples can be found in the occupational domain (for example not all papers have the same importance when an academic apply for tenure or for full professorship). The present paper assesses whether performance increases according to the importance of the task to be undertaken by comparing various theories. Each theory implies a specific relationship between performance and importance. In the first theory, performance is negatively correlated with the Morris-importance, while in the second theory performance is positively correlated with importance. In this paper, we measure the importance of a task not by the Morris-importance criterion but by the HNVimportance criterion. The latter assumes that the agent has a stock of exhaustible efforts and 
chooses the ideal moment to make an effort. An effort is used when the HNV-importance is higher. We test experimentally these two approaches to importance, as well as a simple measure of importance based on critical shots (round/set/match shots). The results show that the Morris-importance fails at predicting players' performance while the HNV allocation variable has a much better predictive value. Moreover, we do not find clear evidence of the existence of choking under pressure: stress, as measured by the Skin Conductance Responses, does not affect performance.

Our criterion of HNV-importance takes into account the trade-off between the stakes and the option value for determining whether it is worthwhile to use an effort or not on a given task. However, the player does not take into account the other player's response to his own play. Our experiment consists of two treatments, the Human treatment and the Robot treatment. In most of our regressions, the HNV allocation variable predicts performance. Introducing strategic concerns in our theoretical framework seems to be an interesting extension that would move our theory from a decision theory setting to a game theory setting.

This study could of course be extended in several other ways. For instance, it could be promising to consider the case under which, after a certain delay, the agent can regain efforts. For example, studies have shown the existence of a momentum effect for the winner of a point in dynamic contests (Gauriot et al. (2014)). The idea that success breeds success could be captured in our model by an increase of the stock of efforts left during the match depending on success at previous important points. A preliminary stage where the agent could choose between two different assets- many lower-efficiency efforts or fewer high-efficiency efforts - could also be considered. Indeed, a player through practice may improve certain characteristics, as with endurance or explosiveness. This may apply to a sports player, but also to a worker who may try to improve either his ability to work long hours on a project (the extensive margin), or his ability to react very quickly and intensively (the intensive margin). It might also be interesting to investigate the relation between efforts and tiredness. Indeed, an effort increases performance in the current task but it may also decrease performance in the following tasks, decreasing the mean performance of the agent in the rest of the competition. The agent 
then faces a trade-off: indeed, making an effort may shorten the competition but it may also negatively affect future performance if the competition lasts. 


\section{References}

Ahmadinejad, A. M., Dehghani, S., Hajiaghayi, M. T., Lucier, B., Mahini, H., and Seddighin, S. (2016). From duels to battlefields: Computing equilibria of blotto and other games. In Proceedings of the Thirtieth AAAI Conference on Artificial Intelligence, AAAI'16, pages 369-375. AAAI Press.

Apesteguia, J. and Palacios-Huerta, I. (2010). Psychological pressure in competitive environments: Evidence from a randomized natural experiment. The American Economic Review, 100(5):2548-2564.

Ariely, D., Gneezy, U., Loewenstein, G., and Mazar, N. (2009). Large stakes and big mistakes. The Review of Economic Studies, 76(2):451-469.

Baumeister, R. F. (1984). Choking under pressure: self-consciousness and paradoxical effects of incentives on skillful performance. Journal of personality and social psychology, 46(3):610.

Baumeister, R. F. and Showers, C. J. (1986). A review of paradoxical performance effects: choking under pressure in sports and mental tests. European Journal of Social Psychology, 16(4):361-383.

Beilock, S. L. and Carr, T. H. (2001). On the fragility of skilled performance: what governs choking under pressure? Journal of Experimental Psychology. General, 130(4):701-725.

Blascovich, J., Seery, M. D., Mugridge, C. A., Norris, R. K., and Weisbuch, M. (2004). Predicting athletic performance from cardiovascular indexes of challenge and threat. Journal of Experimental Social Psychology, 40(5):683-688.

Borel, E. (1921). La théorie du jeu et les équations intégrales à noyau symétrique. Comptes rendus de l'Académie, 173(13041308):97-100.

Buckert, M., Schwieren, C., Kudielka, B. M., and Fiebach, C. J. (2015). How stressful are economic competitions in the lab? an investigation with physiological measures. Technical report, Discussion Paper Series, University of Heidelberg, Department of Economics. 
Chowdhury, S. M., Kovenock, D., and Sheremeta, R. M. (2013). An experimental investigation of colonel blotto game. Economic Theory, 52(3):833-861.

Cohen-Zada, D., Krumer, A., Rosenboim, M., and Shapir, O. M. (2017). Choking under pressure and gender: Evidence from professional tennis. Journal of Economic Psychology, 61(August):176-190.

Cox, C. A. (2017). Rent-seeking and competitive preferences. Journal of Economic Psychology, 63(December):102-116.

Dawson, M. E., Schell, A. M., and Filion, D. L. (2007). The electrodermal system. Handbook of psychophysiology, 159 .

DeCaro, M. S., Carr, T. H., Albert, N. B., and Beilock, S. L. (2011). Choking under pressure: multiple routes to skill failure. Journal of Experimentall Psychology. General, 140(1):390406.

Dechenaux, E., Kovenock, D., and Sheremeta, R. M. (2015). A survey of experimental research on contests, all-pay auctions and tournaments. Experimental Economics, 18(4):609-669.

Deck, C., Gauriot, R., and Page, L. (2017). An experimental investigation of simultaneous multi-battle contests with strategic complementarities. Journal of Economic Psychology, 63(December):117-134.

Dohmen, T. J. (2008). Do professionals choke under pressure? Journal of Economic Behavior \& Organization, 65(3):636-653.

Ely, J., Sarangi, S., and Wiser, M. (2017). Do agents maximise? risk taking on first and second serves in tennis. Journal of Economic Psychology, 63(December):135-142.

Gauriot, R., Page, L., et al. (2014). Does success breed success? a quasi-experiment on strategic momentum in dynamic contests. Technical report, QUT Business School.

González-Díaz, J., Gossner, O., and Rogers, B. W. (2012). Performing best when it matters 
most: Evidence from professional tennis. Journal of Economic Behavior \& Organization, $84(3): 767-781$.

Greiner, B. (2015). Subject pool recruitment procedures: organizing experiments with orsee. Journal of the Economic Science Association, 1(1):114-125.

Hancock, P. A. and Desmond, P. A. (2001). Stress, workload, and fatigue. Lawrence Erlbaum Associates, Publishers.

Herbst, L. (2016). Who pays to win again? the joy of winning in contest experiments. Max Planck Institute for Tax Law and Public Finance Working Paper 6, Max Planck Institute.

Hockey, R. (2013). The Psychology of Fatigue: Work, Effort and Control. Cambridge University Press.

Kali, R., Pastoriza, D., and Plante, J.-F. (2017). The burden of glory: Competing for nonmonetary incentives in rank-order tournaments. Journal of Economic \& Management Strategy.

Kaminsky, K. S., Luks, E. M., and Nelson, P. I. (1984). Strategy, nontransitive dominance and the exponential distribution. Australian Journal of Statistics, 26(2):111-118.

Klumpp, T. and Polborn, M. K. (2006). Primaries and the new hampshire effect. Journal of Public Economics, 90(6):1073-1114.

Kocher, M. G., Lenz, M. V., and Sutter, M. (2012). Psychological pressure in competitive environments: New evidence from randomized natural experiments. Management Science, $58(8): 1585-1591$.

Konrad, K. A. (2009). Strategy and Dynamics in Contests. Oxford University Press.

Konrad, K. A. and Kovenock, D. (2009). Multi-battle contests. Games and Economic Behavior, $66(1): 256-274$.

Kovenock, D., Sarangi, S., and Wiser, M. (2015). All-pay 2 ÃŮ 2 hex: a multibattle contest with complementarities. International Journal of Game Theory, 44(August):571-597. 
Magnus, J. and Klaassen, F. (1998). On the existence of "big points" in tennis: four years at wimbledon. CentER for Economic Research, Tilburg University.

Mago, S. D., Sheremeta, R. M., and Yates, A. J. (2013). Best-of-three contest experiments: Strategic versus psychological momentum. International Journal of Industrial Organization, $31(3): 287-296$.

Malueg, D. A. and Yates, A. J. (2010). Testing contest theory: evidence from best-of-three tennis matches. The Review of Economics and Statistics, 92(3):689-692.

Moore, L. J., Vine, S. J., Wilson, M. R., and Freeman, P. (2012). The effect of challenge and threat states on performance: An examination of potential mechanisms. Psychophysiology, 49(10):1417-1425.

Morris, C. (1977). The most important points in tennis. Optimal strategies in sports, 5:131140.

Norris, J. (1998). Markov Chains, volume 2. Cambridge University Press.

Paserman, M. D. (2007). Gender differences in performance in competitive environments: Evidence from professional tennis players. CEPR Discussion Papers 6335, C.E.P.R. Discussion Papers.

Porcelli, A. J., Lewis, A. H., and Delgado, M. R. (2012). Acute stress influences neural circuits of reward processing. Frontiers in Neuroscience, 6:157.

Rinott, Y., Scarsini, M., and Yu, Y. (2012). A colonel blotto gladiator game. Mathematics of Operations Research, 37(4):574-590.

Rosen, S. (1986). Prizes and incentives in elimination tournaments. American Economic $\underline{\text { Review, } 76: 701-715 .}$

Sanders, S. and Walia, B. (2012). Shirking and âĂIJchokingâ̆̆̇̇ under incentive-based pressure: a behavioral economic theory of performance production. Economics Letters, 116(3):363-366. 
Sheremeta, R. M. (2010). Experimental comparison of multi-stage and one-stage contests. Games and Economic Behavior, 68(2):731-747.

Tullock, G. (1986). Efficient rent seeking. In Buchanan, J., Tollison, R., and Tullock, G., editors, Toward a Theory of the Rent-Seeking Society, pages 97-112. College Station: Texas AM University Press.

Van Long, N. (2013). The theory of contests: A unified model and review of the literature. European Journal of Political Economy, 32(2):161-181.

$\mathrm{Yu}, \mathrm{R}$. (2015). Choking under pressure: the neuropsychological mechanisms of incentiveinduced performance decrements. Frontiers in Behavioral Neuroscience, 9:19. 


\section{A Appendices}

\section{A.1 Illustration of Morris-importance and $\mathrm{HNV}(k)$-importance for tennis scores}

Consider a tennis match between player 1 and player 2. Obviously, they both have the objective to win the match. We do not consider service and receive.

\section{A.1.1 Illustration of Morris-importance and $\mathrm{HNV}(k)$-importance for a single game}

We first focus on a single game and we assume that the player who wins the game is declared victorious. Note that a margin of two points is required. We assume that the probability to win one point is the same for both players $(p=0.5)$.

Illustration of a single game. The X-axis (the Y-axis, respectively) counts the gains of player 1 (player 2, respectively). Each square in Figure A1 represents a potential point. The first square in the lower part of the figure on the left illustrates the starting point in the game $(0,0)$. The square on the right (above) depicts the score if player 1 (player 2) has won the point.

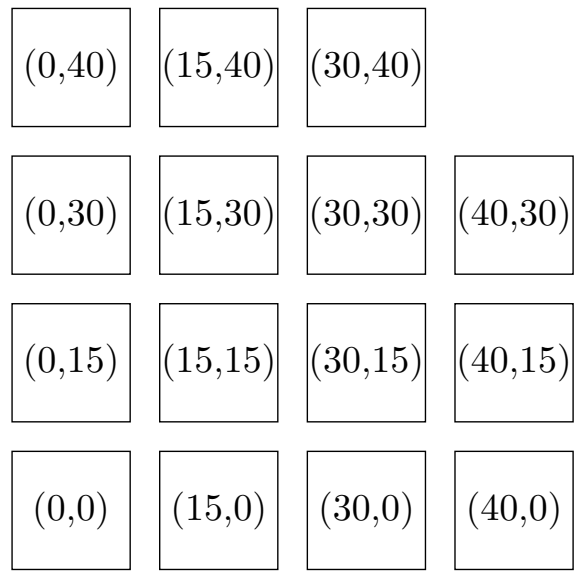

Figure A1: Illustration of a single game. 

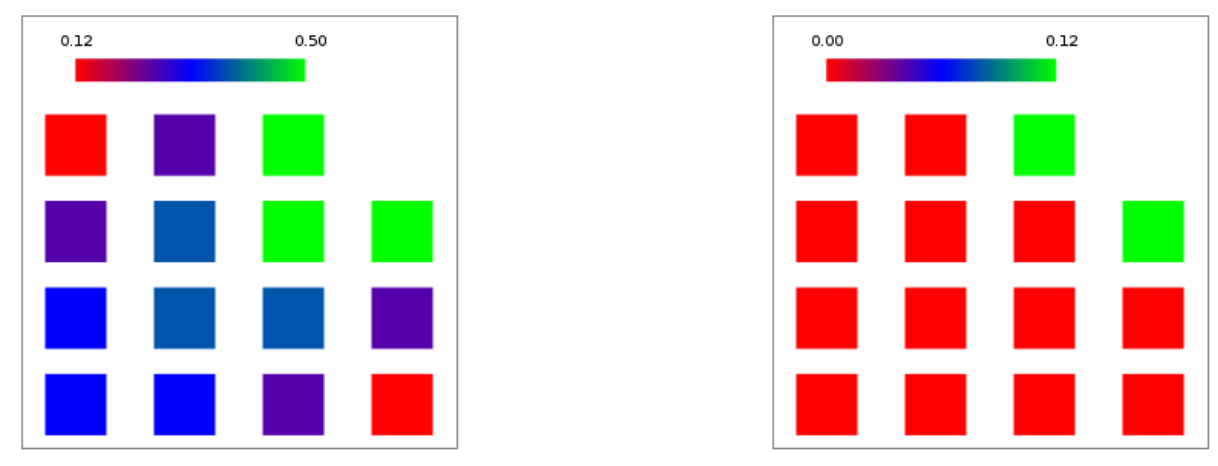

Figure A2: Morris-importance (left) and HNV(1)-importance (right) for all the scores of a single game for $p=0.5$.

Morris-importance and HNV(1)-importance. We calculate, for each point, focusing on player 1's point-of-view, both Morris-importance and HNV(1)-importance. We illustrate these results in Figure A2. The following colour codes are used: green means high importance, light blue means somewhat high, dark blue means medium importance, purple means somewhat low importance and red means low importance.

Note that the two panels in Figure A2 are symmetric. Indeed, the probability of winning one point is the same for both players. First of all, Morris-importance is the highest for the scores $(30,30),(30,40)$ and $(40,30)$. Morris-importance is the lowest when the score difference is equal to three points, i.e. for the scores $(0,40)$ and $(40,0)$. The closer to the end of the game players are, the less likely will it be for the one who loses this point to win the game. In the case of a single effort left there are only two possibilities: the player has incentives to make an effort or not. Player 1 has positive incentives to exert effort only for $(30,40)$ and $(40,30)$. If player 1 wins at $(30,40)$, the score will be a draw $(30,30)$, otherwise he will lose the match. In the case of $(40,30)$, either he wins the match or there is draw.

We consider five different cases:

- For $(30,40)$ and $(40,30)$, the two measures are similar and high. 
- For $(30,30)$ the Morris-importance is high while player 1 has no incentive to make an effort. The intuition is the following. This point is not irreversible. If player 1 loses this point, he can always make an effort subsequently and comes back to draw.

- For $(15,15),(30,15)$ and $(15,30)$, player 1 has no incentives to make an effort. Winning these points modifies the probability of winning the game but these points are not irreversible: it is better to keep the effort and use it latter.

- For scores $(0,0),(0,15)$ and $(15,0)$, Morris-importance is medium while HNV(1)-importance is low.

- For the other scores, the two measures are similar and insignificant.

To conclude, there are only two possibilities: the player has incentives to make an effort or not. The closer to the end of the match players are, the less likely will it be for the player who loses this point to win the game. In other words, the closer to the end of the game the score is, the higher the HNV(1)-importance will be. We also show that the two measures are similar only at the end of a tight game or when the game is fairly one-sided and far from the end.

Two exhaustible efforts and HNV(2)-Importance. We also analyze the situation in which the player has two efforts left. Figure A3 depicts HNV(2)-importance for a single game. Note that when player 1 has two efforts left, the points for which he has incentives to use the first effort are clearly different from those for which he has incentives to use the second. The intuition is the following: with two remaining efforts, the goal is to use the first effort to avoid losing the game with a close score and use the last effort to win the game. 


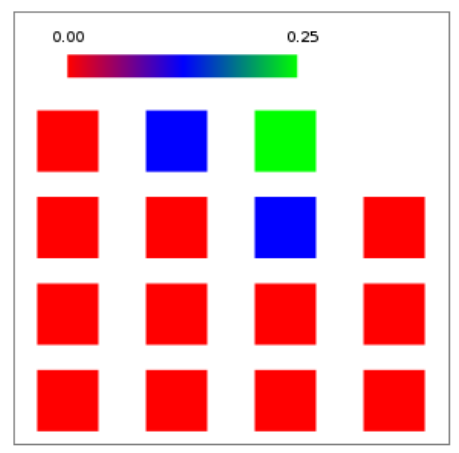

Figure A3: $\operatorname{HNV}(2)$-importance for $p=0.5$.

\section{A.1.2 Morris-importance and HNV(1)-importance for all the scores of a whole match.}

We consider now a whole match and calculate the Morris-importance and the HNV(1)-importance for all the potential points, for the probability $\mathrm{p}=0.5$. The results for a whole match extend the observations for a single game. Figures A4 and A5 illustrate Morris-importance and HNV(1)importance for all the scores of a whole match with $\mathrm{p}=0.5$ and where the first player to win two sets is victorious.

- The X-axis (the Y-axis, respectively) displays the gains of player 1 (player 2, respectively).

- Each small square depicts a point. A game is modeled as previously.

- The same rules as in the experiment are used. The first of the two competitors who wins at least 4 points with at least 2 points ahead of the opponent wins the round. The first of the two competitors who wins 6 rounds wins the set. The first of the two competitors who wins 2 sets wins the match.

- We use the same colour codes as previously: high importance (green), somewhat high 
importance (light blue), middle importance (dark blue), somewhat low importance (purple), low importance (red).

The figures show that the two measures are similar only at the end of a tight match and when the match is fairly one-sided and far from the end. The notion of irreversibility is crucial. When the match is tight, the individual should make an effort on the tasks which lead to an irreversibility: if this point is lost, the victory is almost impossible. 


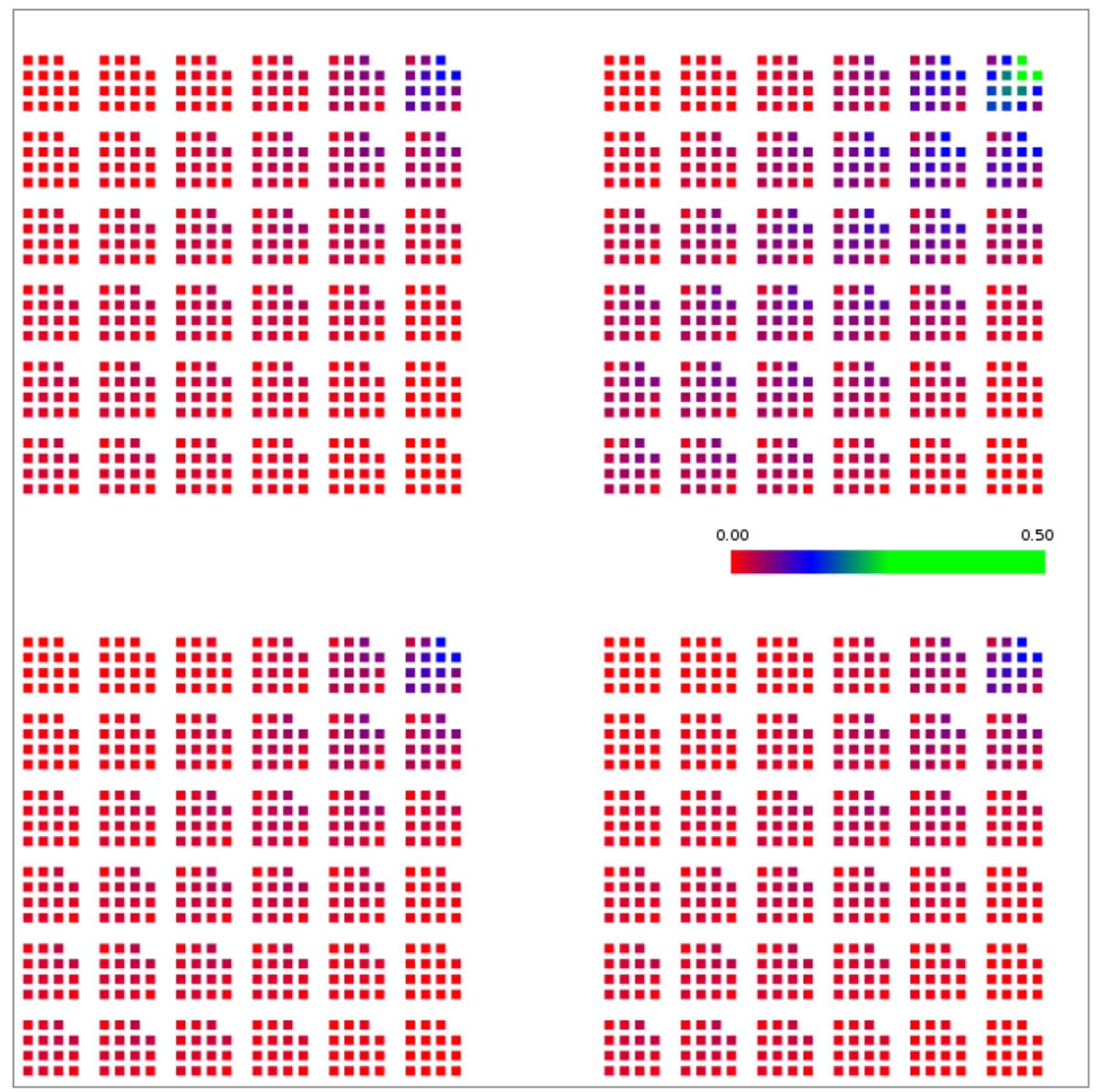

Figure A4: Morris-importance for all the scores of a whole game for $p=0.5$. 


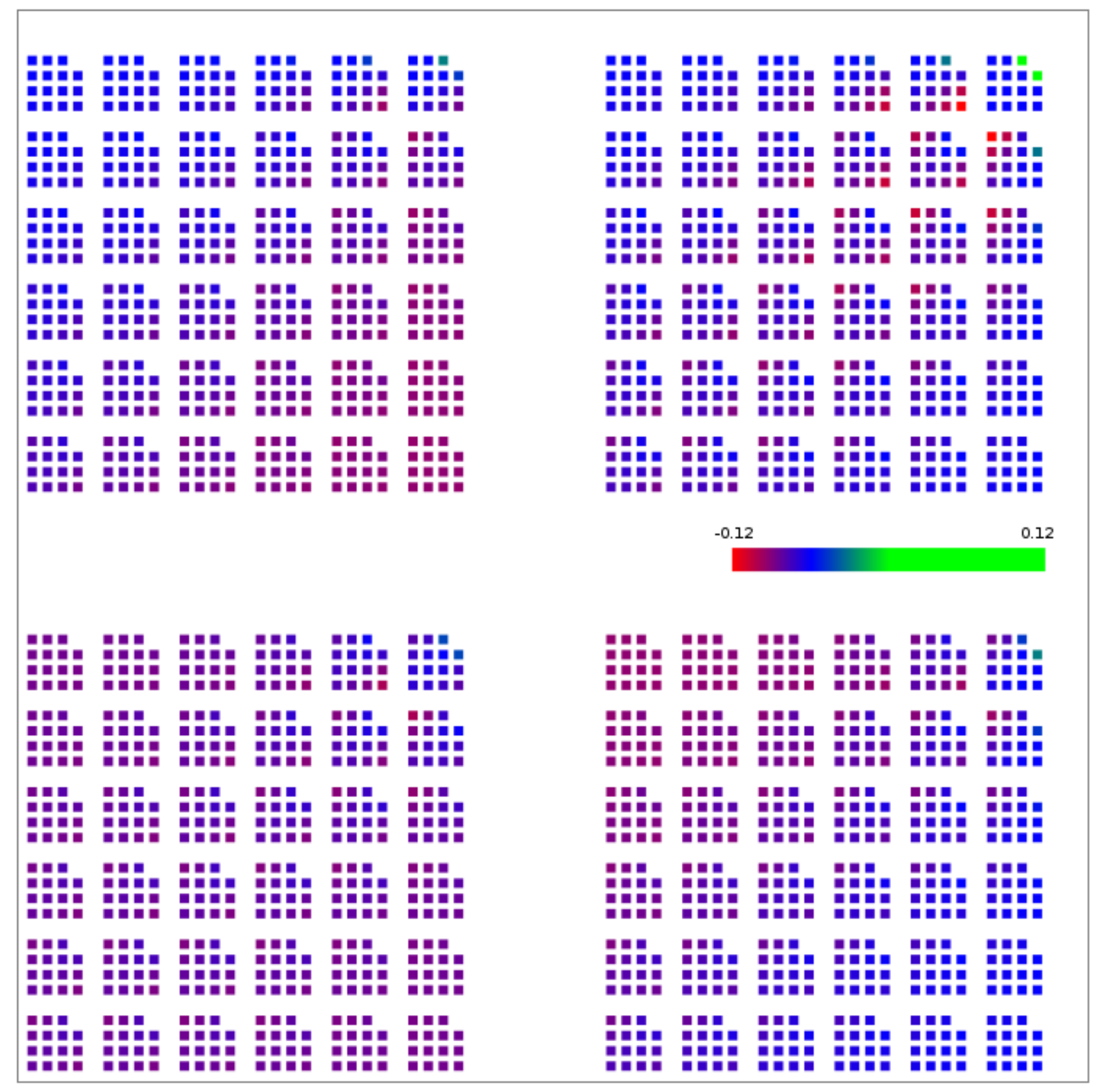

Figure A5: HNV(1)-importance for all the scores of a whole game for $p=0.5$. 


\section{A.2 Instructions for the experiment}

These instructions, translated from French, are both for the Human treatment and the Robot treatment. When the instructions differ between the two treatments, those specific to the Robot treatment are put in italics and between brackets.

We thank you for participating in this experiment in economics in which you can earn a certain amount of money. You will also receive a 5 euros participation fee for showing up on time. You will be paid in cash and in private at the end of the session.

Throughout the session, we ask you not to communicate with other participants. All information entered into the computer will remain anonymous.

\section{Description}

This experiment consists of one part in which you will be paired with one other person in the room. The identity of this person will remain unknown. Similarly, the other person with whom you will be paired will never be informed of your identity. This person will be called your "opponent" in the remainder of these instructions.

[Previous paragraph replaced by the following in the Robot treatment: This experience consists of one part in which you will be paired with one other player. This player is not a person, it is a computer. This player will be called your "opponent" in the remainder of these instructions.]

Your earnings in this part depend on your performance and on that of your opponent during the game. In addition to the participation fee, one of the two co-participants will earn 20 Euros and the other will earn 0 Euro, according to the rules detailed below.

[Previous sentence replaced by the following in the Robot treatment: In addition to the participation fee, you will earn either 20 Euros or 0 Euro, according to the rules detailed below.] 
This part consists of several stages, each of which is divided into several rounds. During each round, we ask you to perform the task described below.

The task The task involves using your mouse pointer to reach the center of a target that appears on your computer screen. You have to shoot as accurately as possible in the center of the target. The level of difficulty differs according to a perturbation of the position of the pointer which is random on each shot. The difficulty is the same for each participant.

Each participant has 8 seconds maximum to shoot. If the shot was not performed before the 8 seconds have elapsed, the distance to the target center is arbitrarily set to 1000 .

During each round, you will have to shoot several times.

JOnly in the Robot treatment:

How does your computer-opponent play?

For each shot from your robot, the program randomly selects a shot among the shots of the human participants in a previous session. During this previous session, only human participants were involved and they were paired together randomly. The "robot shot" is therefore not random: it is the shot of a human participant in a previous session aimed at the center of the target.]

Performance and number of points Your performance in this task is indicated by the distance between the impact of your shot and the center of the target. The shorter this distance, the better your performance.

Once the two co-participants have shot, the performances of the two co-participants are compared. The co-participant with the best performance (that is to say, the lowest distance to the center of the target) scores one point.

In case of a tie between the two co-participants, a random draw determines which of the two participants is awarded the point.

The first of the two co-participants who wins at least 4 points with at least 2 points ahead of the opponent wins the round.

The first of the two co-participants who wins 6 rounds wins the set. 
The first of the two co-participants who wins 2 sets wins the game.

Determination of payoffs Within the pair, if you win the game you earn 20 Euros in addition to your participation fee. If you do not win the game, you earn nothing; you only receive your participation fee.

Information As shown in the screenshot below, the screen displays a target. Below the target you can see a time counter that indicates the remaining time to shoot. After each shot, you are informed on your screen of your performance and that of your opponent. Finally, you are informed as to whether you or your opponent scores the current point. The bottom of the screen permanently shows:

- the number of sets won so far,

- the number of rounds won in the current set,

- the number of points earned in the current round, both for yourself and for your opponent.

Your screen also informs you whether the next shot is a shot that decides the winner of the round, the set or game.

Beginning of the session Before the game starts, you have to make 5 test shots and 10 practice shots. The five test shots are intended to familiarize you with the task. After each shot, you are informed of your own performance (your distance to the center of the target).

The 10 practice shots are used to calculate your ability at this task compared to that of your opponent. After each of these shots, you are informed of your own performance.

After the 10 practice shots, the computer program compares your performance in each of the 10 practice shots to the performance of your opponent in each of those 10 shots, taking into account all the possible combinations of these shots. The shots that have not been done in the allotted time are not included in this calculation. This calculation will tell you what is the theoretical number of chances out of 100 that you should win the point on your opponent for a given shot.

Your performance during these test and practice shots will not be taken into account in 


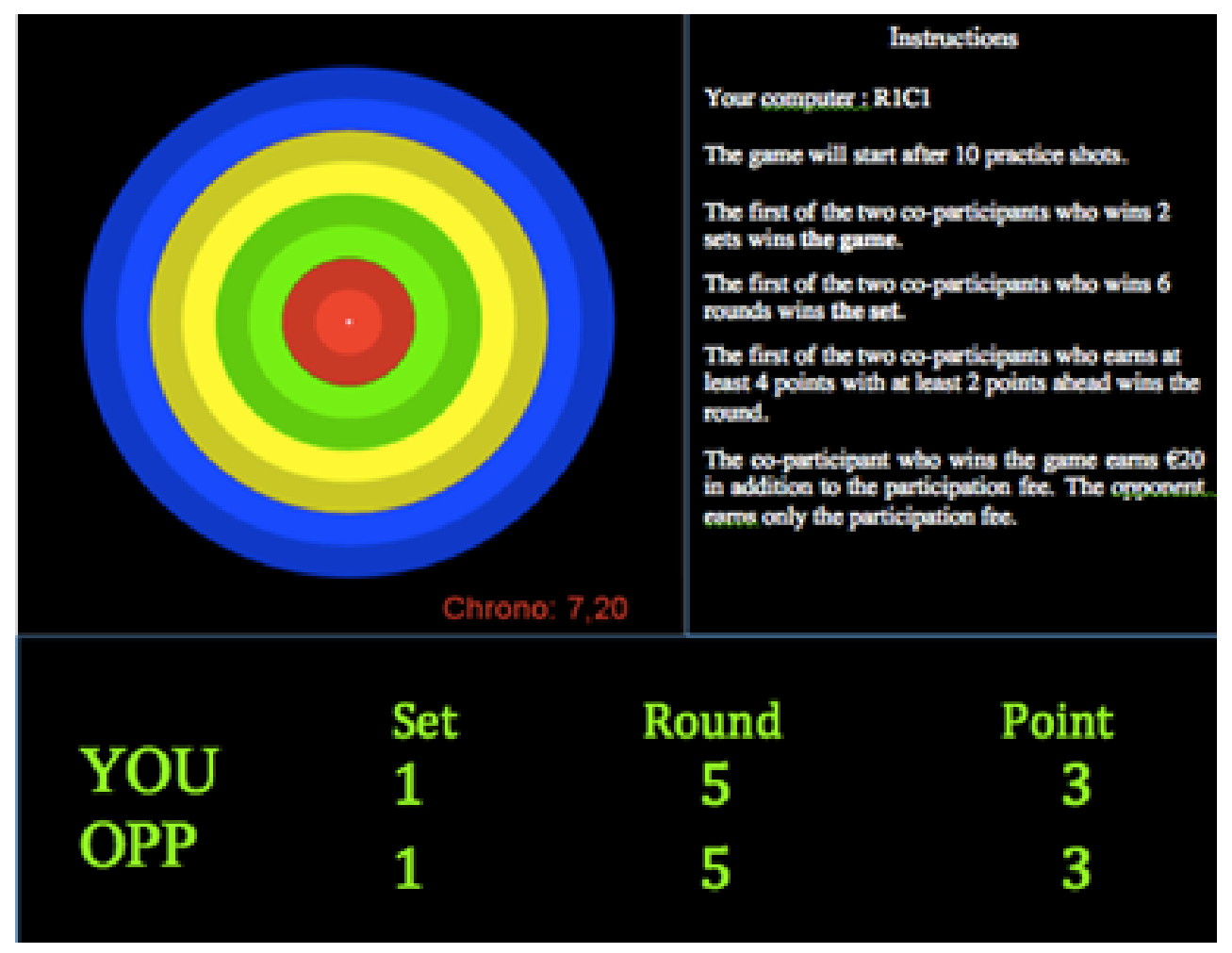

Figure A6: Screenshot of the task. 
calculating the points in the actual game.

End of the session At the end of the game, you will see on your screen a final questionnaire. Once you have completed this questionnaire, we ask you to wait quietly until the end of the session without communicating with other participants. The session will end once all session participants have finished their games. To wait, you can read the magazines that are available on your desk or any document that you brought with you. You can also enjoy all the activities that will be available on your computer screen.

To sum up:

- The task involves shooting at a target.

- The winner of the game earns 20 Euros and the loser gets 0.

- The winner of the game is the one of the two co-participants who won two sets.

- To win a set, one must be the first co-participant to win 6 rounds.*

- To win a round, one must be the first co-participant to win at least 4 points with at least 2 points ahead of his opponent.

Please read these instructions again and answer the questionnaire that was distributed. If you have any question, please raise your hand and we will answer your questions in private. Once you have completed the questionnaire, raise your hand so we can come and check your answers.

\section{Questionnaire}


Thank you for answering these questions to familiarize yourself with the rules of the experiment.

\begin{tabular}{lc}
\hline Propositions & Yes No \\
\hline PRobot treatment: Youplay against another person present mne them $/$
\end{tabular}

[Robot treatment: You play against another person present in the room.] $\quad \mathrm{O} \quad \mathrm{O}$

In a round, imagine the current score:

3 points for participant 1 and 2 points for participant 2 .

- Does participant 1 win the round by winning the next point? $\quad$ O O

- Does participant 2 win the round by winning the next point? $\quad \mathrm{O} \quad \mathrm{O}$

Does a participant win the set as soon as the participant

$\begin{array}{lll}\text { has won one round more than the opponent? } & \mathrm{O} & \mathrm{O}\end{array}$

$\begin{array}{lll}\text { The game ends as soon as a participant has won two sets. } & \mathrm{O} & \mathrm{O}\end{array}$

$\begin{array}{lll}\text { The earnings of each set are } 20 \text { Euros. } & \mathrm{O} & \mathrm{O}\end{array}$

$\begin{array}{lll}\text { There may be three sets in the game. } & \mathrm{O} & \mathrm{O}\end{array}$

$\begin{array}{lll}\text { There may be four sets in the game. } & \mathrm{O} & \mathrm{O}\end{array}$ 


\section{A.3 Determinants of performance in the Robot treatment}

\begin{tabular}{|c|c|c|c|c|c|}
\hline $\begin{array}{l}\text { Dep. variable: } \\
\text { Distance to center }\end{array}$ & $\begin{array}{c}10 \text { efforts } \\
\text { (1) }\end{array}$ & $\begin{array}{c}20 \text { efforts } \\
(2)\end{array}$ & $\begin{array}{c}30 \text { efforts } \\
\text { (3) }\end{array}$ & $\begin{array}{l}40 \text { efforts } \\
(4)\end{array}$ & $\begin{array}{c}50 \text { efforts } \\
(5)\end{array}$ \\
\hline Complexity & $\begin{array}{c}0.640^{* * * *} \\
(0.018)\end{array}$ & $\begin{array}{c}0.640^{* * *} \\
(0.018)\end{array}$ & $\begin{array}{c}0.640^{* * *} \\
(0.018)\end{array}$ & $\begin{array}{c}0.640^{* * *} \\
(0.018)\end{array}$ & $\begin{array}{c}0.640^{* * *} \\
(0.018)\end{array}$ \\
\hline HNV allocation variable & $\begin{array}{l}-0.216 \\
(0.247)\end{array}$ & $\begin{array}{l}-0.084 \\
(0.222)\end{array}$ & $\begin{array}{l}-0.181 \\
(0.177)\end{array}$ & $\begin{array}{l}-0.121 \\
(0.180)\end{array}$ & $\begin{array}{c}0.403 \\
(0.506)\end{array}$ \\
\hline Distance Practice & $\begin{array}{c}0.973^{* * *} \\
(0.084)\end{array}$ & $\begin{array}{c}0.972^{* * *} \\
(0.084)\end{array}$ & $\begin{array}{c}0.972^{* * *} \\
(0.083)\end{array}$ & $\begin{array}{c}0.975^{* * *} \\
(0.081)\end{array}$ & $\begin{array}{c}0.968 * * * \\
(0.084)\end{array}$ \\
\hline Time to shoot & $\begin{array}{l}<-0.001 \\
(<0.001)\end{array}$ & $\begin{array}{l}<-0.001 \\
(<0.001)\end{array}$ & $\begin{array}{l}<-0.001 \\
(<0.001)\end{array}$ & $\begin{array}{l}<-0.001 \\
(<0.001)\end{array}$ & $\begin{array}{l}<-0.001 \\
(<0.001)\end{array}$ \\
\hline Shot number & $\begin{array}{c}0.001 \\
(0.002)\end{array}$ & $\begin{array}{c}0.001 \\
(0.002)\end{array}$ & $\begin{array}{l}<0.001 \\
(0.002)\end{array}$ & $\begin{array}{l}<0.001 \\
(0.002)\end{array}$ & $\begin{array}{l}<0.001 \\
(0.002)\end{array}$ \\
\hline SCR measure & $\begin{array}{l}-0.132 \\
(0.093)\end{array}$ & $\begin{array}{l}-0.133 \\
(0.093)\end{array}$ & $\begin{array}{l}-0.133 \\
(0.093)\end{array}$ & $\begin{array}{l}-0.128 \\
(0.092)\end{array}$ & $\begin{array}{l}-0.131 \\
(0.094)\end{array}$ \\
\hline SCR magnitude & $\begin{array}{c}0.908^{* * *} \\
(0.296)\end{array}$ & $\begin{array}{c}0.913^{* * *} \\
(0.296)\end{array}$ & $\begin{array}{c}0.909^{* * *} \\
(0.295)\end{array}$ & $\begin{array}{c}0.913^{* * *} \\
(0.293)\end{array}$ & $\begin{array}{c}0.922^{* * *} \\
(0.297)\end{array}$ \\
\hline Male & $\begin{array}{l}-0.065 \\
(0.133)\end{array}$ & $\begin{array}{l}-0.065 \\
(0.134)\end{array}$ & $\begin{array}{l}-0.065 \\
(0.134)\end{array}$ & $\begin{array}{l}-0.068 \\
(0.131)\end{array}$ & $\begin{array}{l}-0.066 \\
(0.133)\end{array}$ \\
\hline Age & $\begin{array}{l}-0.018 \\
(0.012)\end{array}$ & $\begin{array}{l}-0.019 \\
(0.012)\end{array}$ & $\begin{array}{l}-0.019 \\
(0.012)\end{array}$ & $\begin{array}{l}-0.018 \\
(0.012)\end{array}$ & $\begin{array}{l}-0.019 \\
(0.012)\end{array}$ \\
\hline Tennis & $\begin{array}{l}-0.084 \\
(0.093)\end{array}$ & $\begin{array}{l}-0.082 \\
(0.092)\end{array}$ & $\begin{array}{l}-0.083 \\
(0.092)\end{array}$ & $\begin{array}{c}-0.073 \\
(0.0991)\end{array}$ & $\begin{array}{l}-0.077 \\
(0.092)\end{array}$ \\
\hline Constant & $\begin{array}{c}-4.111^{* * *} \\
(0.619)\end{array}$ & $\begin{array}{c}-4.089^{* * *} \\
(0.610)\end{array}$ & $\begin{array}{c}-4.060 * * * \\
(0.616)\end{array}$ & $\begin{array}{c}-4.103^{* * *} \\
(0.604)\end{array}$ & $\begin{array}{c}-4.059^{* * *} \\
(0.621)\end{array}$ \\
\hline $\mathrm{Nb}$ observations & 5100 & 5100 & 5100 & 5100 & 5100 \\
\hline $\mathrm{Nb}$ clusters & 33 & 33 & 33 & 33 & 33 \\
\hline $\mathrm{F}$ & 413.37 & 415.64 & 414.39 & 484.39 & 408.85 \\
\hline $\mathrm{p}>\mathrm{F}$ & $<0.001$ & $<0.001$ & $<0.001$ & $<0.001$ & $<0.001$ \\
\hline $\mathrm{R} 2$ & 0.192 & 0.192 & 0.192 & 0.192 & 0.192 \\
\hline
\end{tabular}

Note: All models are OLS regressions with robust standard errors (in parentheses) clustered at the individual level. ***, ${ }^{* *}$ and $*$ indicate significance at the $1 \%$ level, $5 \%$ level and $10 \%$ level, respectively.

Table A1: Determinants of performance in the Robot treatment, based on the homogenous HNV importance. 